\title{
ERRORS IN BOILER EFFICIENCY STANDARDS
}

\author{
Fred D. Lang, P.E. \\ Exergetic Systems, Inc. \\ San Rafael, California 94901 \\ Lang@ExergeticSystems.com
}

\begin{abstract}
This paper presents both criticism and suggested changes to boiler efficiency standards associated with fossil-fired steam generators. These standards include the widely used ASME PTC 4.1 and DIN 1942, and their replacements ASME PTC 4:2008 and the European EN 12952-15. For these standards it is useful to review both old and new. The chief criticism lies with inconsistent application of thermodynamic principles. Conceptual errors are made with reference temperatures and with shaft powers. This paper advocates for the Input/Loss Method.

When using computed fuel flow as a touchstone, it becomes obvious that arbitrary use of reference temperatures and/or use of capricious energy credits cannot produce a consistent (absolute) computed fuel flow. Efficiency, calorific value and fuel flow must have fixed definitions concomitant with a system's useful energy flow. Thermodynamics is not an arbitrary discipline, the computed fuel flow of a system must describe the actual needs. Boiler efficiency requires consistent treatment, producing consistent and absolute fuel and emission flows.

Boiler efficiencies and associated calorific values have obvious standing when judging contractual obligations, for thermal performance monitoring, and for confirming carbon emissions. Note that a 0.5 to $1 \%$ change in efficiency may well have significant financial consequences when testing a new unit, or the on-going costs associated with fuel and carbon taxes. This paper demonstrates that errors greater than $2 \%$ are entirely possible if following the current standards. This paper appeals to the resolution of efficiency at the $0.1 \%$ level.

The power plant engineer is encouraged to read the Introduction and Summary \& Recommendations sections while the thermodynamicist is requested to throughly
\end{abstract}

review and critique the mid-sections. The author hopes such reviews, at a minimum, will advocate for more open discussion.

PAPER-80.WPD, Rev 30E

\section{NOMENCLATURE}

Note that much of the following nomenclature is taken from Exergetic Systems' Input/Loss Method and its steam generator simulator, EX-FOSS (Lang, 2012a).

\section{Molar Quantities Related to Stoichiometrics}

$b_{\mathrm{A}}=$ Moles of water in combustion air, moles/base

$\mathrm{b}_{\mathrm{Z}}=$ Moles of water in-leakage, moles/base

$\mathrm{b}_{\mathrm{S}}=$ Moles of pure sorbent injected, moles/base

$\mathrm{n}_{\mathrm{j}}=$ Moles of product $\mathrm{j}$ at boundary, w/o leakage

$\mathrm{n}_{\text {Ideal-j }}=$ Moles of ideal product $\mathrm{j}$, without leakage

$\mathrm{n}_{\mathrm{S}-\mathrm{H} 2 \mathrm{O}}=$ Moles of sorbent product hydrate at boundary

$\mathrm{N}_{\mathrm{k}}=$ Molecular weight of substance $\mathrm{k}$

$\mathrm{x}=$ Moles of fuel $/ 100$ moles dry product (base)

$\mathrm{z}_{\mathrm{S}}=$ Moles of $\mathrm{H}_{2} \mathrm{O}$ per sorbent product

$\mathrm{Z}_{\mathrm{H}}=$ Moles of hydrogen per gaseous fuel

$\alpha_{\mathrm{k}}=$ Moles of As-Fired fuel constituent $\mathrm{k}$

$\beta=$ Molar ratio of air leakage to combustion air

$\gamma_{\mathrm{S}}=$ Moles of excess sorbent per pure sorbent $b_{\mathrm{S}}$.

\section{Quantities Related to System Terms}

$\mathrm{CV}=$ Calorific Value

$\mathrm{HBC}=$ Firing Correction relative to $\mathrm{T}_{\mathrm{CAL}}, \Delta \mathrm{Btu} / \mathrm{lb}_{\mathrm{AF}}$

$\mathrm{HHV}=$ Fuel gross $\mathrm{CV}$ at constant volume, $\mathrm{Btu} / \mathrm{lbm}_{\mathrm{AF}}$

HHVP $=$ As-Fired gross CV corr. for constant pressure

HNSL $=$ Non-Chemistry \& Non-Stack Losses.

$\mathrm{HPR}_{\text {Act }}=$ Enthalpy of Products, actual As-Fired.

$\mathrm{HPR}_{\text {Ideal-XX }}=$ Enthalpy of ideal products at $\mathrm{T}_{\mathrm{CAL}}$, see

"Subscripts" for XX, Btu/ $/ \mathrm{lbm}_{\mathrm{AF}}$.

$\mathrm{HRX}_{\text {Act }}=$ Enthalpy of Reactants, actual As-Fired. 
$\mathrm{HRX}_{\mathrm{CAL}-\mathrm{XX}}=$ Enthalpy of generic reactants at $\mathrm{T}_{\mathrm{CAL}}$.

$\mathrm{J}=$ Energy conversion, $778.16926 \mathrm{ft}-\mathrm{lbf} / \mathrm{Btu}$

$\mathrm{LHV}=$ Fuel net $\mathrm{CV}$ at constant volume, $\mathrm{Btu} / \mathrm{lbm}_{\mathrm{AF}}$

LHVP $=$ As-Fired net CV corr. for constant pressure

$\mathrm{m}_{\mathrm{AF}}=$ As-Fired fuel mass flow rate, $\mathrm{lbm}_{\mathrm{AF}} / \mathrm{hr}$

$\mathrm{Q}_{\mathrm{WF}}=$ "Useful Energy Flow Developed" to working

fluid from combustion gases, Btu/hr

$\mathrm{R}=$ Gas constant, $1545.325 \mathrm{ft}-\mathrm{lbf} / \mathrm{lb}-\mathrm{mole} / \mathrm{R}$

$\mathrm{T}_{\mathrm{CAL}}=$ Calorimetric temperature, ${ }^{\circ} \mathrm{F}$

$\mathrm{T}_{\mathrm{RA}}=$ Ambient air temp., ref. for PTC 4.1 and $4.4,{ }^{\circ} \mathrm{F}$

$\mathrm{T}_{\text {Stack }}=$ Exit (Stack) boundary temperature, ${ }^{\circ} \mathrm{F}$

$\mathrm{W}_{\mathrm{ID}}=$ Fan powers regards outlet streams, Btu/hr

$\eta_{\mathrm{A}}=$ Boiler absorption efficiency, unitless

$\eta_{\mathrm{B}}=$ Boiler efficiency, unitless

$\Delta \mathrm{H}_{A \text {-CAL-CaSO4 }}^{0}=$ Heat of Association of $\mathrm{CaSO}_{4}$ hydrates

$\Delta \mathrm{H}_{D \text {-CAL-Sorb }}^{0}=$ Heat of Disassociation (e.g., Trona)

at $\mathrm{T}_{\mathrm{CAL}}, \Delta \mathrm{Btu} / \mathrm{lb}$-mole.

$\Delta \mathrm{H}_{F-\mathrm{CAL}-\mathrm{k}}^{0}=$ Heat of Form. of $\mathrm{k}$ at $\mathrm{T}_{\mathrm{CAL}}, \Delta \mathrm{btu} / \mathrm{lb}$-mole

$\Delta \mathrm{H}_{f \text {-CAL-H2O }}^{0}=$ Heat of Formation, sat. liquid at $\mathrm{T}_{\mathrm{CAL}}$

$\Delta \mathrm{H}_{g-\mathrm{CAL}-\mathrm{H} 2 \mathrm{O}}^{0}=$ Heat of Formation, sat. vapor at $\mathrm{T}_{\mathrm{CAL}}$

$\Delta \mathrm{H}_{\mathrm{LH}}=$ Enthalpy correction for net $\mathrm{CV}, \Delta \mathrm{Btu} / \mathrm{lbm}_{\mathrm{AF}}$

$\Delta \mathrm{H}_{\mathrm{V} / \mathrm{P}}=$ Enthalpy correction for volume, $\Delta \mathrm{Btu} / \mathrm{lbm}_{\mathrm{AF}}$

$\Delta \mathrm{PV} \mathrm{V}_{\mathrm{LH}}=\mathrm{PV}$ energy correction from net to gross $\mathrm{CV}$

$\Delta \mathrm{U}_{\mathrm{LH}}=$ Internal energy correction from net to gross.

\section{Subscripts}

$\mathrm{AF}=$ As-Fired fuel (wet with mineral matter).

$\mathrm{CAL}=$ Calorimetric, as in calorimetric temperature.

$\mathrm{CF}=$ Calorimetric Fuel (wet with mineral matter) referenced to dry $\mathrm{O}_{2}$ at $\mathrm{T}_{\mathrm{CAL}}$.

$\mathrm{CM}=$ Calorimetric Fuel with Moist Air (and other reactants) all at $\mathrm{T}_{\mathrm{CAL}}$.

$\mathrm{HHV}=$ Gross calorific value, higher heating value

$\mathrm{LHV}=$ Net calorific value, lower heating value .

\section{INTRODUCTION TO STANDARDS}

This section discusses boiler efficiency standards and summarizes their problems. No present boiler efficiency standard addresses calorimetric fundamentals. Although more fully explained in subsequent sections, this statement means that the method of determining the energy content of a fossil fuel dictates the method by which the performance of that fuel is judged when burned to make thermal power. The practical justification for such a statement lies with fuel water plus fuel hydrogen (thus product water).

Boiler efficiency as taught by industrial standards using an Input-Output Method is fundamentally:

$$
\eta_{\mathrm{B}}=\begin{gathered}
\text { [Useful Energy Flow Developed }] \\
/[\text { Fuel Energy Flow Supplied }]
\end{gathered}
$$

Although a simple expression, historically there are any number of interpretations of the terms comprising its numerator and denominator. For example, ASME PTC 4:2008 states (\$3-1.2) that one may compute over a dozen different values of boiler efficiency using various interpretations of the same data set! This paper argues there is only one method, a method leading to a consistent and unique computation of fuel and emission flows.

Definitions must be explained concerning both a steam generator as a "system" and then its "state". Applied thermodynamics is defined by a boundary; most boiler efficiency standards err with their boundary assumptions.

The boundary of a fossil-fired steam generator being studied for thermal efficiency does not encompass all physical equipment, but rather the constraining volume of its interacting fluids, for example: fuel conveyance, combustion gas confinement, the inside of air ducts and working fluid pipe IDs. This boundary derives from the principle that the thermal efficiency of a steam generator only addresses how the As-Fired fuel interacts with its gas/air/working fluids.

Extraneous equipment has no impact on boiler efficiency if not directly affecting the fuel's interaction with the gas/air/working fluids. This definition is consistent with the concept of the fuel's calorific value. It immediately excludes such equipment as pulverizers, steam driven pumps, recirculation pumps, and the like. ASME PTC 4 and DIN 1942 would suggest that a higher pulverizer shaft power will increase boiler efficiency. However, pulverizer power has no impact on the interaction of fuel and gas/air/ working fluids (the grinding of coal is emulated during lab preparation of samples). A recirculation pump has no impact on fuel heating the working fluid. The metric boiler efficiency must solely guide the engineer towards reduced fuel flow and $\mathrm{CO}_{2}$ emissions while making adequate steam. Shaft powers are monitored through house load.

A system in equilibrium with its medium, from which no power is extracted, defines its dead state (Keenan, 1941). For an active steam generator, having the potential for thermal power, the condition of its dead state is often confused with its "reference state". The dead state limits how much potential power is possible, an ultimate limit to actual output, the numerator of Eq.(1). For steam generators, the dead state should be taken as the coldest medium associated with the local environment. For an actual steam generator, its thermal power as derived from a given fuel flow are absolutes, established by considering unambiguous differences between reference states (main steam less feedwater, etc.). In engineering, all energy levels are relative to a chosen reference state. Text books will argue that reference states are arbitrary, a simple enough concept when dealing with a single fluid. Water 
properties for example, normally referenced to the triple point, could be referenced to the boiling point at 1 atmosphere, resulting in the same Useful Energy Flow Developed of Eq.(1).

However, for this discussion we are not concerned with the numerator of Eq.(1), but rather treatment of the denominator. Note that although Eq.(1) expresses an InputOutput approach, conversion to specific values immediately invokes a Heat Loss Method (herein termed the "Energy Balance Method"); but the two must produce identical efficiencies. The argument here is for absolutes in the denominator, that the "arbitrariness" of reference states can not be defined by the casual analyst but, indeed, is established when defining the energy content of the fuel. The technician determining calorific value of natural gas may be required run his/her calculations using a national standard, e.g., $0.0^{\circ} \mathrm{C}$ for France, $15^{\circ} \mathrm{C}$ for Ireland and the U.K., $25^{\circ} \mathrm{C}$ for Germany, $60^{\circ} \mathrm{F}\left(15.56^{\circ} \mathrm{C}\right)$ for North America, etc. (see ISO 12213-3:2006, ISO 13443:1996 /Cor 1:1997, and AGA Report No. 3), or another yet. For solid and liquid fossil fuels the reference temperature may be viewed by some as arbitrary, but in fact is also set by the technician running the bomb calorimeter, not the casual analyst. For an adiabatic or isoperibol bomb calorimeter, its reference is the "calorimetric temperature" at which the bomb's water jacket is kept in an equilibrium state.

It is well understood that calorific values vary with temperature. Natural gas evaluated at $0.0^{\circ} \mathrm{C}$ is different than that at $25^{\circ} \mathrm{C}$, a bomb run at $50^{\circ} \mathrm{F}$ will yield a different value for the same coal as one run at $120^{\circ} \mathrm{F}$. Because AsFired conditions are relative to a reference temperature, boiler efficiency will vary with reference temperature. That said, the objective of this paper - and the proposed objective of all efficiency standards - is an absolute understanding of a steam generator's thermal performance, the fuel it consumes, consistent with a defined boundary and actual emission flow. If Eq.(1)'s numerator is an absolute measure of thermal power, we can not allow an arbitrary denominator (implying an arbitrary fuel flow). However, recognizing that boiler efficiency varies with temperature is no justification for standards advocating relative efficiencies, but rather, efficiency equations which properly correct for reference temperature. The test for absolutes is computed fuel flow, a fuel mass flow which justifies the developed output. A temperature dependent $\mathrm{CV}$ leads to a temperature dependent boiler efficiency, but corrected to the actual firing conditions and thus producing consistent, and absolute, fuel \& emission flows.

The act of choosing a calorimetric temperature to either compute (for gaseous fuels) or to measure (for solid and liquid fuels) a calorific value does not give the casual analyst the liberty to then choose another for reference. For any multi-fluid system, only a consistent thermodynamic reference state can be considered or the laws of thermodynamics will not be satisfied. It is not acceptable to assume one energy level for the fuel, another for the working fluid, another for the combustion gases, another for the dry combustion air, and yet another for moisture in the combustion air. As examples: the air's nitrogen and fuel make combustion products; sorbents, tube leaks and soot blowing add to products; the air's moisture affects products; and combustion products heat working fluid.

\section{ERRORS, WHAT ERRORS ?}

Addressed are three types of errors and uncertainties involving thermodynamic concepts, procedural problems, and measurements which impact efficiency:

1) System conceptual errors are made when:

a) mis-using reference temperatures;

b) when treating certain system components, especially shaft powers (i.e., "credit" terms); and

c) when not understanding the energy of reactants.

2) Procedural errors are made which impact thermodynamics in a generic manner; e.g., the definition of dry air, use of consistent molecular weights, enthalpic references of fluids which are mixed within the system, thermodynamic properties, etc.

3) Measurement uncertainties such as those found in the lab regards fuel chemistry and CVs, certain loss terms (HNSL), and uncertainties in plant data which affect $\mathrm{Q}_{\mathrm{WF}}$ and thus back-calculated fuel and emission flows.

For all of these, the author argues for an accuracy criteria at the $\pm 0.1 \% \Delta \eta_{\mathrm{B}}$ level. What this means is that system concepts and procedures affecting a computational efficiency at $\geq \pm 0.1 \% \Delta \eta_{\mathrm{B}}$ must be included. This is not to say all system concepts and procedures are to be understood at this level, but are to be included given a computational sensitivity thus demonstrated. Although coal analysis between laboratories should lie within \pm 100 $\Delta \mathrm{Btu} / \mathrm{lbm}( \pm 233 \Delta \mathrm{kJ} / \mathrm{kg})$, modern bomb calorimeters are quoted as having $0.1 \% \Delta \mathrm{HHV} / \mathrm{HHV}$ repeatability. It is this fact which adds imperative. The author's EX-FOSS program allows for an error calculation based on stoichiometric inconsistencies (as-tested emissions versus assumed fuel chemistry), which if $> \pm 0.1 \% \Delta \eta_{\mathrm{B}}$, and unexplained, results in repeating the test. It is noteworthy that ASME PTC 4 (§5-7.3) expresses this same opinion, that "a convergence limit of $0.1 \%$ efficiency is sufficient".

A clear example of the mis-use and capricious nature of current boiler efficiency standards is witnessed by the comments made at a 2009 TAPPI conference. The conference authors appear to be searching for a standard which would produce the highest efficiency to minimize "taxation and legislative problems"; their comments are stunning (Vakkilainen \& Ahtila, 2009). 
Set out below are errors made in traditional boiler efficiency standards. This list is by no means complete, but concentrates on "credits" and reference temperatures.

\section{ASME PTC 4.1 (United States):}

This code was superseded in 1998 by ASME PTC 4. Although PTC 4.1 is no longer an ASME code nor an ANSI standard, it is included here given its continued use and historic precedence.

$\S 1.04 .5$, shaft powers from pulverizers and circulating pumps are included as energy credits.

$\$ 7.2 .8 .1$, reference temperature is taken as the air's ambient temperature $\left(\mathrm{T}_{\mathrm{RA}}\right)$.

§7.2.8.1 and Appendix, nitrogen content in dry air is fixed at $76.85 \%$ (an assumed weight fraction).

$\S 7.3$, "heat credits" appear in the numerator and denominator.

The FD and ID fans are considered outside the thermodynamic envelope.

The standard's Input-Output and Heat Loss Methods are inconsistent (see the DIN 1942 discussion).

This standard applies to any fossil fuel.

\section{ASME PTC 4 (United States):}

The original 1998 release was superseded with a 2008 release to which the following are referenced.

$\S 5-5$, the defined fuel energy flow ignores the as-fired state (if different from $77^{\circ} \mathrm{F}$ ), this would especially destroy any accuracy of gas-fired efficiencies given typical firing from $45^{\circ} \mathrm{F}$ to $60^{\circ} \mathrm{F}$.

$\S 5-7$, "fuel efficiency" is PTC 4's preferred method, fuel energy is not corrected to the as-fired.

$\$ 5-7.1$, "credits" appear only in the numerator.

$\S 5-8.1$, the conversion from constant volume to constant pressure ignores nitrogen and oxygen bound in the fuel, oxygen is an important term when considering high oxygenated fuels (such as PRB); such PTC 4 conversion is not temperature dependent.

$\S 5-9$, sorbent energy flows are normalized to the as-fired fuel, which ignores unique sensible energies.

$\S 5-9.5 .1, \S 5-9.5 .2, \S 5-11.1, \S 5-11.4 .1$, etc., oxygen content in dry air is fixed at $20.95 \%\left(\mathrm{Ar}\right.$ and $\mathrm{CO}_{2}$ are not included, molar air/oxygen $=3.7733$ ) .

$\$ 5-11.2$, psychrometric properties should be extended to $-40 \mathrm{~F}$, as applicable for steam generators found in norther climes; caution should be exercised when using reference psychrometric temperatures; the standard employs a water to dry air ratio of 0.6220 (i.e., textbook), PTC 4 data would suggests 0.6398 .

$\S 5-13.1$, the reference temperature is set constant at $25^{\circ} \mathrm{C}$

$\S 5-15.5 .1$ and $\S 5-15.5 .2$, shaft powers are included as energy credits.

$\S 5-19.8$, the enthalpy of natural gas should be computed, and is easily done given known properties.

$\S 5-19.11$ and $\$ 5-19.12$, "average" combustion gas properties are erroneously employed, such use is hardly justified given the wide applicability this standard is assumed to have; the referenced 1971 JANAF/NASA properties are out-of-date (other citations, appearing political, are quite current).

The FD and ID fans are considered outside the thermodynamic envelope.

The 2008 release (unlike the 1998 version) relates to coal-, oil- and gas-fired steam generators.

DIN 1942 (German):

This code was superseded by DIN EN 12952-15:2004. The following nomenclature and comments are specific to DIN 1942 (Feb. 1994).

$\S 6.2$, the reference temperature $\left(t_{b}\right)$ is set at $25^{\circ} \mathrm{C}$. However, "other temperatures may be agreed upon" by correcting the net calorific value with fuel, air and combustion gas sensible heat terms.

\$6.3.2.3, so-called "heat credits" (denoted as $\mathrm{Q}_{\mathrm{Z}}$ ) includes shaft powers from pulverizers, recirculating gas fans, working fluid circulating pumps and "power from any other motors".

$\S 6.4$, DIN 1942 employs the $\mathrm{Q}_{Z}$ term in both its InputOutput and Heat Loss Methods. In DIN 1942: $\mathrm{Q}_{\mathrm{N}}$ is the useful output (herein $\mathrm{Q}_{\mathrm{WF}}$ ); $\mathrm{Q}_{\mathrm{ZB}}$ is the fuel energy $\left(\mathrm{m}_{\mathrm{AF}} \mathrm{LHVP}\right)$; and $\mathrm{Q}_{\mathrm{Vtot}}$ is the loss term.

$$
\begin{aligned}
& \eta_{\mathrm{B}-\mathrm{LHV}}=\frac{\mathrm{Q}_{\mathrm{N}}}{\mathrm{Q}_{\mathrm{ZB}}+\mathrm{Q}_{\mathrm{Z}}} \\
& \eta_{\mathrm{B}-\mathrm{LHV}}=1.0-\frac{\mathrm{Q}_{\mathrm{Vtot}}}{\mathrm{Q}_{\mathrm{ZB}}+\mathrm{Q}_{\mathrm{Z}}}
\end{aligned}
$$

For Eq.(DIN-147) an increase in $\mathrm{Q}_{Z}$ will always increase $\eta_{\mathrm{B}-\mathrm{LHV}}$ provided $\mathrm{Q}_{\mathrm{Vtot}}>0.0$. However, the same increase in $\mathrm{Q}_{Z}$ will always decrease the Input-Output efficiency of Eq.(DIN-144), thus guaranteeing inconsistent computed fuel flows. This same conundrum exists with PTC 4.1, with PTC 4 and its "gross efficiency" definition, and with other standards.

\$6.3.4.1, oxygen content in dry air is fixed at $20.938 \%$ ( $\mathrm{Ar}$ is not included, air/oxygen $=3.7760$ ).

\section{Draft European Standard:}

The following comments reference prEN 12952-15 of Nov. 1999, which is now issued as EN 12952-15. The draft and the new closely follow DIN 1942, employing its nomenclature and general methods.

$\S 7.2$, the reference temperature $\left(t_{b}\right)$ is set at $25^{\circ} \mathrm{C}$, but "other temperatures may be agreed upon" which corrects heat credits as done in DIN 1942.

$\S 7.3 .4 .1$, oxygen content in dry air is fixed at $20.938 \%$ (Ar is not included but apparently $\mathrm{CO}_{2}$ is included, 
air/oxygen $=3.7760$ ) .

\$7.4.3.2, energy credits appear only in the denominator.

The ID fan is considered outside the envelope; the FD

fan may be considered inside the envelope.

This standard applies to any fossil fuel.

\section{BS 2885 (British):}

The following comments reference BS 2885:1974; which has been superseded by the British Standards Institute (BSI) issue of BS EN 12952-15:2003 (basically the revised DIN 1942).

$\$ 2$ (bottom), all fuels shall use a "calorimetric temperature" of $25^{\circ} \mathrm{C}$.

Section E and Section F, Item 434, the standard expects that flue gas nitrogen is to be measured, thus dry air is not specified.

Items 708, 804 and 907 (and Notes), the reference temperature for sensible heats in the dry flue gas, moisture in the combustion air and fuel is the combustion air temperature (per ASME PTC 4.1), not $25^{\circ} \mathrm{C}$ as its stated "calorimetric temperature".

Item 901 (and Notes) regards "Method A" (InputOutput) it does not consider energy credits; it invokes a simple "fuel efficiency" in which the CV bears no Firing Correction. However Item 902, invoking the Heat Loss Method ("Method B") considers the "heat equivalent of auxiliary power" as a loss, carrying the same sign as the radiation \& convection loss. Such inconsistencies will result in impossible differences in computed fuel flows.

Energy credits (shaft powers) appear only in the denominator of its Heat Loss Method.

This standard applies to any fossil fuel.

\section{Standard for Recovery Boilers Used in the Pulp \& Paper Industry (United States):}

This standard was prepared by the Technical Association of the Pulp and Paper Industry (TAPPI,1996) and was based on a 1993 draft of ASME PTC 4 using its energy balance method; however there appears to be some controversy in Europe when applying this standard (Vakkilainen \& Ahtila,2009).

$\S 0$ (page 4), the reference temperature is set at $77^{\circ} \mathrm{F}$.

$\S 7.1 .4 .1$ and $\$ 7.1 .4 .3$, oxygen content in dry air is fixed at $23.14 \%$ (a carry-over from ASME PTC 4.1, but used as a molar ratio and is not correct) .

For recovery boilers, burning black liquor fuel, is it common industrial practice to correct the measured heating value for Heats of Formation for the reduction of $\mathrm{Na}_{2} \mathrm{SO}_{4}$. Such corrections address the difference between ideal combustion products associated with a bomb calorimeter versus actual products associated with further reduction of certain black liquor compounds. Such corrections are thermodynamically inconsistent, as the calorific value is corrected with a computed $\Delta \mathrm{HR}$ term: (HHVP - $\triangle \mathrm{HR}+\mathrm{HBC}$ ).

This standard applies only to recovery boilers burning sodium-laced black liquor.

\section{CONCEPTUAL AND PROCEDURAL ERRORS}

Standards have no monopoly on conceptual errors. Previous versions of the Input/Loss Method did not properly recognize energies of reactants; it used a complicated set of corrections which now appear frenetic. The present approach (this Rev. 30) greatly simplifies when developing Eqs.(3) thru (4C). They demonstrate that gross and net reactant and product terms are identical.

Most observed conceptual errors are associated with product water, formed from the fuel's entrained water and from bound hydrogen. Thus, conceptual errors associated with the calorimetric temperature for highly energetic fuels, with low product water, are slight and typically do not meet the $0.1 \% \Delta \eta_{\mathrm{B}}$ criteria. However, conceptual errors associated with fuels producing $10 \%$ or more product water (such as high volatile B bituminous (hvBb), to PRB coal, to the lignites and peat) are appreciable, ranging from $0.2 \%$ to the $0.8 \% \Delta \eta_{\mathrm{B}}$ level assuming a 18 $\Delta^{\circ} \mathrm{F}\left(10 \Delta^{\circ} \mathrm{C}\right)$ change in calorimetric temperature. Such errors derive from assuming a reference temperature for boiler efficiency calculations, while the calorific value was determined at another. For example, a $0.5 \% \Delta \eta_{\mathrm{B}}$ error is made for Powder River Basin (PRB) coal when $25^{\circ} \mathrm{C}$ is the assumed reference, while the $\mathrm{CV}$ was determined at $35^{\circ} \mathrm{C}$.

Conceptual errors may also exist when not recognizing the sensitivity of the ratio of ambient oxygen to dry air. A change of ambient oxygen from $21 \%$ to $20.5 \%$ represents a decrease of $0.253 \% \Delta \eta_{\mathrm{B}-\mathrm{HHV}}$ for a typical PRB fired unit assuming a constant Stack $\mathrm{O}_{2}$; a $1.128 \% \Delta \eta_{\mathrm{B}-\mathrm{HHV}}$ decrease for $19 \%$ ambient. Of the steam generators tested by the author, typically 1 in 10 were found to have degraded ambient oxygen levels typically caused either by a weather inversion, still air or flue gas leakage into FD Fans. The NASA (1976) standard ambient oxygen is $20.9476 \%$ at sea level.

Conceptual errors are also made when following the current standards (low water fuels aside) which involve the treatment of shaft powers, discussed in the next section.

Procedural errors are made by not adhering to the latest thermodynamic standards. The author finds it rare that any two standards use the same molecular weights. Inconsistency is present in air psychrometric properties (see ASHRAE procedures, discussed below). One would expect to use the same fundamental methods when evaluating a combustion turbine versus a conventional steam generator (ASME PTC 22 assumes $60^{\circ} \mathrm{F}$ as a base, conversion is allowed per its $\S 4.12$, versus ASME PTC 4).

Precise methods offer little comfort if laboratories 
cannot record $\mathrm{CVs}$ with at least repeatability, if not also with accuracy. Although the $0.1 \% \Delta \eta_{\mathrm{B}}$ criteria is meet in repeatability when using the modern bomb calorimeter, we must remember that variability found in CVs (say from grab sampling) may, indeed, be quite real. Standards must present a practical statistical treatment of multiple lab chemistries and CVs, as would be associated with testing a coal-fired unit. It is noteworthy that ASME PTC 4 devotes its Section 7 to uncertainty analysis. Although Section 7 is clearly amenable for academic pursuits, it is not something most power plant engineers are going to place under their pillows. The coal-fired industry needs procedures, fully integrated within the standards for evaluating a test:

1) Consistency of individual as-tested fuel chemistries, rejecting any $\mathrm{CV}$ given an outlying chemistry [one solution is to apply techniques afforded in the OxyHydrocarbon model (see Lang \& Canning, 2007)];

2) Define a steady state period by examining time plots of feedwater and fuel flows (over at least $15 \mathrm{~min}$.), the averaged data resulting in $\mathrm{Q}_{\mathrm{WF}}$ [although such plots have been used by the author and his colleagues for years, the precedence for this is 125 years old! (Kent, 1884)];

3) Tolerance on a proper Energy Balance Method efficiency, as based on items only affecting calorific value (i.e., sampling) and $\mathrm{Q}_{\mathrm{WF}}$; and

4) A consistent boiler efficiency, allowing the calculation of an absolute fuel flow.

\section{CONSISTENT BOILER EFFICIENCY}

The temperature used to operate a bomb calorimeter, or to compute a gaseous $\mathrm{CV}$, is the beginning point for developing consistent thermodynamics. Calorific values for solid or liquid fuels are obtained either by adiabatic or isoperibol bomb calorimetry following ASTM D5865 or ISO 1928:1995(E). An adiabatic bomb calorimeter detects the gross energy liberated from ideal combustion, burned in pure $\mathrm{O}_{2}$, by maintaining a constant water bath temperature about the bomb, which defines the calorimetric temperature, $\mathrm{T}_{\mathrm{CAL}}$. An isoperibol bomb calorimeter detects the net energy liberated by accurately monitoring the water bath temperature, its resultant average value being $\mathrm{T}_{\mathrm{CAL}}$. Many modern bomb calorimeters are automated to run at a programmable $\mathrm{T}_{\mathrm{CAL}}$. The author has found various labs in North America and Europe using $27^{\circ} \mathrm{C}\left(80.6^{\circ} \mathrm{F}\right), 28.5^{\circ} \mathrm{C}\left(83.3^{\circ} \mathrm{F}\right), 30^{\circ} \mathrm{C}\left(86^{\circ} \mathrm{F}\right)$ and, commonly, $35^{\circ} \mathrm{C}\left(95^{\circ} \mathrm{F}\right)$. Up thru 2007 the author could not find any laboratory in North America or in Europe determining coal $\mathrm{CVs}$ at $25^{\circ} \mathrm{C}$, the reference for most standards!

Boiler efficiency should be a simple reflection of what the technician, determining CV by either calculation or measurement, has produced. The calorimetric process begins with reactants, the combustion event, and ends with ideal products of $\mathrm{CO}_{2}, \mathrm{SO}_{2}$ and $\mathrm{H}_{2} \mathrm{O}$. This process is path dependent, the traditional path is to maintain an essentially constant temperature of the calorimeter's heat sink. When mimicking this calorimetric process when applied to a steam generator, the thermodynamicist need only account for: losses associated with actual product streams; all reactants (moist air, sorbents, leakages, etc.); and sensible heats accounting for the fact that reactants may not be fired at the calorimetric temperature. This then is the conversion efficiency of burning fuel, delivering a "Useful Energy Flow Developed" from combustion; i.e., its interaction with gas/air/working fluid. If consistent fuel and emiussion flows are to be computed from boiler efficiency, $\mathrm{Q}_{\mathrm{WF}}$ must only reflect heating from combustion gases. The execution of these concepts is a bit more involved.

The definition of gross calorific value (higher heating value) as based on a bomb calorimeter is the energy liberated from products formed relative to the calorimetric temperature, this includes, of course, the water produced as reduced to the liquid state. We do not measure net values (lower heating values). The internal energy liberated from a constant volume bomb is relative to the equilibrium temperature at which the bomb functioned, as described by the following:

$$
\oint \partial \mathrm{Q}_{\mathrm{T}-\mathrm{Cal}}=-\mathrm{HHV}=-\mathrm{HHVP}+\Delta \mathrm{H}_{\mathrm{V} / \mathrm{P}}
$$

Note that Eq.(2) is path dependent, for a traditional bomb calorimeter, industrial practice sets this path as one having a constant bath temperature. By correcting for PV work, via $\Delta \mathrm{H}_{\mathrm{V} / \mathrm{P}}$, conversion is made from a constant volume internal energy (HHV) to an enthalpy base (HHVP).

A fuel's calorific value, after conversion, is the difference between the enthalpy of ideal combustion products $\left(\mathrm{HPR}_{\text {Ideal-CF-HHV }}\right)$ and the enthalpy of the reactants (HRX $\mathrm{Hal}_{\text {CF-HHV }}$ ) as ideally oxidized in bone-dry $\mathrm{O}_{2}$, and both evaluated at that temperature at which these quantities were formed, at $\mathrm{T}_{\mathrm{CAL}}$. From First Law conservation, Eq.(2) results in the following expressions, descriptive of a "calorimetric system" (i.e., measured or computed). The net CV base of Eq.(3B) is justified below.

$$
\begin{aligned}
& \text { HHVP }=- \text { HPR }_{\text {Ideal-CF-HHV }}+\text { HRX }_{\text {CAL-CF-HHV }} \\
& \text { LHVP }=- \text { HPR }_{\text {Ideal-CF-LHV }}+\text { HRX }_{\text {CAL-CF-LHV }}
\end{aligned}
$$

However, there is additional complexity. When we either measure or compute a $\mathrm{CV}$, we employ dry $\mathrm{O}_{2}$ to produce idea products, thus there are no compound formations, reactants or products, not directly associated with the pure fuel; i.e., a calorimetric system. Of course, since all streams are at $T_{C A L}$ there is no sensible heat. In a calorimetric system, there is no product water formed which does not derive from the fuel; it being condensed (a 
gross $\mathrm{CV}$ ), or not (a net CV). However, when analyzing a system using moist combustion air, the Heat of Formation of the air's water must be accounted when evaluating the actual Heat of Reactants. We must track separately that water associated with the fuel, verus ambient moisture ... and all other reactants. For example, consider 1.0 mole of moist methane being burnt in moist oxygen. The following suggests how $\mathrm{HRX}_{\mathrm{CAL-CF}}$ must be computed:

For a gross $\mathrm{CV}$ base, all at $\mathrm{T}_{\mathrm{CAL}}$ :

$$
\begin{array}{r}
\left\{0.9\left[\mathrm{CH}_{4}\right]+0.1\left[\mathrm{H}_{2} \mathrm{O}\right]\right\}_{\text {As-Fired }}+1.8\left[\mathrm{O}_{2}\right]+0.3\left[\mathrm{H}_{2} \mathrm{O}\right]_{\text {Vap }} \\
\Rightarrow 0.9\left[\mathrm{CO}_{2}\right]+1.9\left[\mathrm{H}_{2} \mathrm{O}\right]_{\mathrm{Liq}}+0.3\left[\mathrm{H}_{2} \mathrm{O}\right]_{\text {Vap }}
\end{array}
$$

For a net $\mathrm{CV}$ base, all at $\mathrm{T}_{\mathrm{CAL}}$ :

$$
\begin{gathered}
\left\{0.9\left[\mathrm{CH}_{4}\right]+0.1\left[\mathrm{H}_{2} \mathrm{O}\right]\right\}_{\text {As-Fired }}+1.8\left[\mathrm{O}_{2}\right]+0.3\left[\mathrm{H}_{2} \mathrm{O}\right]_{\text {Vap }} \\
\Rightarrow>0.9\left[\mathrm{CO}_{2}\right]+2.2\left[\mathrm{H}_{2} \mathrm{O}\right]_{\text {Vap }}
\end{gathered}
$$

As an example of the molar nomenclature used below, in these reactions: $\mathrm{x}=1.0 ; \alpha_{\mathrm{CO} 2}=0.9 ; \mathrm{b}_{\mathrm{A}}=0.3 ; \mathrm{n}_{\mathrm{CO} 2}=0.9$; etc. In all systems, the gross $\mathrm{CV}$ reflects the condensation of product water derived only from the As-Fired fuel (at $\mathrm{T}_{\mathrm{CAL}}$ ). Also, as a fine point, it is not credible to suggest that, for example, if a gaseous fuel contains $\mathrm{CO}_{2}$ or water, or coal contains water with a leakage of working fluid, or combustion air bears moisture, that ideal combustion products cannot be defined consistent with Eq.(3).

Thus by adding the Heats of Formation of non-fuel reactants to HRX $\mathrm{CAL-CF}_{\text {of }}$ Eq.(3), we form an energy of combined fuel and non-fuel reactants, all at $\mathrm{T}_{\mathrm{CAL}}$, termed HRX $_{\text {CAL-CM. }}$ To balance Eq.(3), such treatment implies that the energy of ideal combustion products now reflects non-fuel reactants, termed $\mathrm{HPR}_{\text {Ideal-CM}}$; thus:

$$
\begin{aligned}
& \text { HHVP }=- \text { HPR }_{\text {Ideal-CM-HHV }}+\mathrm{HRX}_{\text {CAL-CM-HHV }} \\
& \text { LHVP }=- \text { HPR }_{\text {Ideal-CM-LHV }}+\mathrm{HRX}_{\text {CAL-CM-LHV }}
\end{aligned}
$$

where:

$$
\begin{aligned}
& \text { HRX }_{\text {CAL-CM-HHV }} \\
& =\text { HRX }_{\text {CAL-CF-HHV }}+\left[\text { Non-Fuel } \Delta \mathrm{H}_{F-\mathrm{CAL}-\mathrm{k}}^{0}\right] \\
& =\mathrm{HHVP}+\mathrm{HPR}_{\text {Ideal-CF-HHV }}+\left[\text { Non-Fuel } \Delta \mathrm{H}_{F-\mathrm{CAL-k}}^{0}\right] \\
& =\mathrm{HHVP}+\left[\left(\mathrm{n}_{\text {Ideal-CO2 }} \Delta \mathrm{H}_{F-\mathrm{CAL}-\mathrm{CO} 2}^{0}\right)\right. \\
& +\left(\mathrm{n}_{\text {Ideal-SO2 }} \Delta \mathrm{H}_{F-\mathrm{CAL}-\mathrm{SO} 2}^{0}\right)+\left(\mathrm{n}_{\text {Ideal-H2O }} \Delta \mathrm{H}_{f-\mathrm{CAL}-\mathrm{H} 2 \mathrm{O}}^{0}\right) \\
& +\mathrm{b}_{\mathrm{A}}(1.0+\beta) \Delta \mathrm{H}_{g-\mathrm{CAL}-\mathrm{H} 2 \mathrm{O}}^{0}+\mathrm{b}_{\mathrm{Z}} \Delta \mathrm{H}_{f-\mathrm{CAL}-\mathrm{H} 2 \mathrm{O}}^{0} \\
& \left.+\mathrm{b}_{\mathrm{S}}\left(1.0+\gamma_{\mathrm{S}}\right)\left(\Delta \mathrm{H}_{F-\text { CAL-Sorb }}^{0}-\Delta \mathrm{H}_{D \text {-CAL-Sorb }}^{0}\right)\right] /\left(\mathrm{xN}_{\mathrm{AF}}\right)
\end{aligned}
$$

$$
\begin{aligned}
& \text { HRX }_{\text {CAL-CM-LHV }} \\
& \quad=\text { HRX }_{\text {CAL-CF-LHV }}+\left[\text { Non-Fuel } \Delta \mathrm{H}_{F-C A L-k}^{0}\right] \\
& \quad=\text { LHVP }+ \text { HPR }_{\text {Ideal-CF-LHV }}+\left[\text { Non-Fuel } \Delta \mathrm{H}_{F-\text { CAL-k }}^{0}\right]
\end{aligned}
$$

$$
\begin{aligned}
& =\mathrm{LHVP}+\left[\left(\mathrm{n}_{\text {Ideal-CO2 }} \Delta \mathrm{H}_{F-\mathrm{CAL}-\mathrm{CO} 2}^{0}\right)\right. \\
& +\left(\mathrm{n}_{\text {Ideal-SO2 } 2} \Delta \mathrm{H}_{F \text {-CAL-SO2 }}^{0}\right)+\left(\mathrm{n}_{\text {Ideal-H2O }} \Delta \mathrm{H}_{g \text {-CAL-H2O }}^{0}\right) \\
& +\mathrm{b}_{\mathrm{A}}(1.0+\beta) \Delta \mathrm{H}_{g \text {-CAL-H2O }}^{0}+\mathrm{b}_{\mathrm{Z}} \Delta \mathrm{H}_{f \text {-CAL-H2O }}^{0} \\
& \left.+\mathrm{b}_{\mathrm{S}}\left(1.0+\gamma_{\mathrm{S}}\right)\left(\Delta \mathrm{H}_{F \text {-CAL-Sorb }}^{0}-\Delta \mathrm{H}_{D \text {-CAL-Sorb }}^{0}\right)\right] /\left(\mathrm{xN}_{\mathrm{AF}}\right)
\end{aligned}
$$

As observed, Eq.(3) is substituted into Eq.(4A) for $\mathrm{HRX}_{\mathrm{CAL}-\mathrm{CF}}$ allowing HRX $\mathrm{CAL}_{\mathrm{CM}}$ to be computed using Eq.(4B3) or Eq.(4C3). In summary, since the thermal efficiency of an ideal system described by Eqs.(3) or (4A) is unity, it follows that either Eqs.(3) or (4A) must serve as the basis for all boiler efficiency standards.

\section{FIRING CORRECTIONS}

When developing an expression for boiler efficiency, the As-Fired fuel's energy content must be corrected for sensible heat relative to $\mathrm{T}_{\mathrm{CAL}}$. Note that firing fuel at $10^{\circ} \mathrm{C}$ or $100^{\circ} \mathrm{C}$ cannot affect its interaction with the gas/air/working fluids, if properly referenced to $\mathrm{T}_{\mathrm{CAL}}$. As analysts we should be able to run calorimeters at any temperature, fire the fuel at any other temperature, without bias to the concept of ideal combustion, without affecting thermodynamic principles, and still compute an absolute fuel flow. Thus by simply adding a "Firing Correction" term (HBC) to each side of Eq.(4A), we bring the reactants term to the As-Fired, maintaining unity $\eta_{\mathrm{B}}$ :

$$
\begin{aligned}
\mathrm{HHVP}+\mathrm{HBC} & =-\mathrm{HPR}_{\text {Ideal-CM-HHV }} \\
& +\mathrm{HRX}_{\mathrm{CAL}-\mathrm{CM}-\mathrm{HHV}}+\mathrm{HBC} \\
\mathrm{LHVP}+\mathrm{HBC} & =-\mathrm{HPR}_{\text {Ideal-CM-LHV }} \\
& +\mathrm{HRX}_{\mathrm{CAL-CM}-\mathrm{LHV}}+\mathrm{HBC}
\end{aligned}
$$

Note that the signs associated with Eqs.(3), (4) \& (5) yield to the convention of a positive calorific value (note that the numeric value of $\mathrm{HPR}_{\text {Ideal }}$ is always $<0.0$, and $\mathrm{HRX}_{\mathrm{CAL}}$ is typically $<0.0$ ). The efficiency of a system described by Eq.(5) is unity. Eq.(5) is interesting in that no condition of any reactant stream will cause departure from unity efficiency given all are at $\mathrm{T}_{\mathrm{CAL}}$. Bone dry or fogged combustion air, nor size of FD Fan, nor steam-air heating, nor sorbent flow, nor water leakage, etc. will affect boiler efficiency per se. Such situations only affect inlet streams. Although entering the system not at $\mathrm{T}_{\mathrm{CAL}}$, and so corrected by $\mathrm{HBC}$, under ideal conditions all products exit at $\mathrm{T}_{\mathrm{CAL}}$.

The next developmental step is to degrade from the ideal by accounting for losses. How thermodynamic losses are grouped may be treated in any number of ways. For this work, they are based on specific energy terms $(\mathrm{Btu} / \mathrm{lbm})$, and are described by $\sum$ Losses $/ \mathrm{m}_{\mathrm{AF}}$. If just subtracting losses from $\mathrm{HPR}_{\text {Ideal-CM, Eq.(5) becomes }}$ unbalanced without an efficiency term. Thus use of either gross efficiency $\left(\eta_{\mathrm{B}-\mathrm{HHV}}\right)$ or net efficiency $\left(\eta_{\mathrm{B}-\mathrm{LHV}}\right)$ to achieve conservation. The $\mathrm{HPR}_{\text {Ideal-CM }}$ term being at $\mathrm{T}_{\mathrm{CAL}}$. 


$$
\begin{aligned}
& \eta_{\mathrm{B}-\mathrm{HHV}}(\mathrm{HHVP}+\mathrm{HBC})= \\
& {\left[-\mathrm{HPR}_{\text {Ideal-CM-HHV }}-\sum \text { Losses } / \mathrm{m}_{\mathrm{AF}}\right]} \\
& + \text { HRX }_{\mathrm{CAL-CM}-\mathrm{HHV}}+\mathrm{HBC} \\
& \eta_{\mathrm{B}-\mathrm{LHV}}(\mathrm{LHVP}+\mathrm{HBC})= \\
& {\left[- \text { HPR }_{\text {Ideal-CM-LHV }}-\text { LLosses } / \mathrm{m}_{\mathrm{AF}}\right]} \\
& + \text { HRX }_{\mathrm{CAL-CM}-\mathrm{LHV}}+\mathrm{HBC}
\end{aligned}
$$

The computed boiler efficiencies follow directly, noting that in Eq. (7) the actual Enthalpy of Reactants $\left(\mathrm{HRX}_{\mathrm{Act}}\right)$ was substituted for $\left[\mathrm{HRX}_{\mathrm{CAL}-\mathrm{CM}}+\mathrm{HBC}\right]$ :

$$
\begin{aligned}
& \eta_{\mathrm{B}-\mathrm{HHV}}= \\
& \frac{-\mathrm{HPR}_{\text {Ideal-CM-HHV }}-\frac{\sum \text { Losses } / \mathrm{m}_{\mathrm{AF}}+\mathrm{HRX}_{\mathrm{Act}-\mathrm{HHV}}}{\mathrm{HHVP}+\mathrm{HBC}}}{\eta_{\mathrm{B}-\mathrm{LHV}}=} \\
& \frac{-\mathrm{HPR}_{\text {Ideal-CM-LHV }}-\frac{\sum \text { Losses } / \mathrm{m}_{\mathrm{AF}}+\mathrm{HRX}_{\mathrm{Act}-\mathrm{LHV}}}{\mathrm{LHVP}+\mathrm{HBC}}}{}
\end{aligned}
$$

In summary, Firing Corrections are to be judged only if they correct to the As-Fired condition. Since Firing Corrections can not affect departure from unity efficiency (only losses), any consideration of a Firing Correction which does not maintain this concept will produce error.

- Any standard not specifying the use of a Firing Correction term, based on calorimetrics, applied in both numerator and denominator of a proper Energy Balance equation, per Eq.(7), is in error. The concept of "fuel efficiency" is meaningless for industrial standards. It is remarkable that as reaffirmed in 1991, ASME PTC 4.1 employed "heat credits" in both its numerator and denominator, and not seven years later PTC 4 employed "credits" only in the numerator.

- A standard allowing for pulverizer electrical power to be added as a "credit" is an error. Pulverizer shaft power adds nothing to the process of fuel interacting with gas/air/working fluid, other than preparing coal's surface energy for combustion. However this action is replicated when preparing a sample for bomb calorimetry. Grinding a brittle substance effects its surface energy, not internal energy; if not ground to a optimum surface/mass, its full chemical energy cannot be realized. If HHV differences between mesh sizes used in the lab versus that produced by pulverizing could be determined, then a correction to HHV (not the Firing Corrections) is entirely justified. Although such direct comparisons are quite difficult as coal's mineral matter grinds differentially, work was initiated which may be helpful in developing a corrective chart for HHV if mesh sizes are greatly different (Lang,2011 and its Figs. 3 \& 4).

- A standard allowing the ambient air temperature to be taken as the reference is in error. For example, some standards would allow a natural gas $\mathrm{CV}$ to be computed at $60^{\circ} \mathrm{F}$, referenced at $95^{\circ} \mathrm{F}$ and fired at $45^{\circ} \mathrm{F}$ with a computed fuel flow known but to God. The only applicable reference temperature for such a case is the calorimetric at $60^{\circ} \mathrm{F}$.

- A standard not appreciating that the reference states of the various fluids (working fluid leakage, gas, dry air, air's moisture, etc.) must be referenced to the same condition, is allowing for First Law violation; steam generators mix all fluids. For example, North America's ASHRAE psychrometric properties share a unique strangeness, where dry air is taken from $0.0^{\circ} \mathrm{F}\left(-17.8^{\circ} \mathrm{C}\right)$ and water from its triple point; this is absurd when addressing boiler in-leakage. For more strangeness, ISO 12213, reflecting national standards, specifies that different reference temperatures may be employed for natural gas $\mathrm{CV}$ versus that used for volume metering (for example, Germany employs CVs at $25^{\circ} \mathrm{C}$, but flows are metered at a $0.0^{\circ} \mathrm{C}$ reference).

- A boiler standard which allows, for example, circulating pump power to affect boiler efficiency is in error. A working fluid pump power associated with the steam generator must be subtracted from $\mathrm{Q}_{\mathrm{WF}}$, as $\mathrm{Q}_{\mathrm{WF}}$ must only reflect the Useful Energy Flow Developed to the working fluid from combustion gases. Such manipulations should be kept apart from a determination of efficiency.

\section{BOILER EFFICIENCY}

The individual terms in these expressions may now be defined and expanded; see Lang (2009a, 2009b) for details. It is tacitly assumed that back-correcting an as-measured calorific value (HHV) of a solid or liquid fossil fuel to some chosen $\mathrm{T}_{\mathrm{CAL}}$ is not possible given chemical complexities of such fuels. It is for this reason that the reactant term $\mathrm{HRX}_{\mathrm{CAL}-\mathrm{CF}}$ is evaluated using Eq.(3).

As regarding loss terms, although differing techniques may be employed, the above fundamentals must be followed; specifically anything affecting an ideal product stream (i.e., $\mathrm{HPR}_{\text {Ideal-CM}}$ ) is a loss and will decrease efficiency and increase computed fuel flow. Different procedures divide the $\sum$ Losses term of Eq.(7) into different categories. Exergetic Systems separates $\sum$ Losses into effluent (stack) related quantities, reflected in its $\mathrm{HPR}_{\text {Act }}$ term, and non-effluent quantities termed "Non-Chemistry \& Non-Stack Losses" (HNSL). 
$\eta_{\mathrm{B}-\mathrm{HHV}}=\frac{-\mathrm{HPR}_{\mathrm{Act}-\mathrm{HHV}}-\mathrm{HNSL}+\mathrm{HRX}_{\mathrm{Act}-\mathrm{HHV}}}{\mathrm{HHVP}+\mathrm{HBC}}$

$\eta_{\mathrm{B}-\mathrm{LHV}}=\frac{-\mathrm{HPR}_{\mathrm{Act}-\mathrm{LHV}}-\mathrm{HNSL}+\mathrm{HRX}_{\mathrm{Act}-\mathrm{LHV}}}{\mathrm{LHVP}+\mathrm{HBC}_{-}}$

This separative treatment allows definition of the actual product term without differentiating "stack losses" (as used in the standards) from actual combustion products; it eliminates formulation problems of PTC 4, EN 12952-15, DIN 1942, etc. The actual quantities are evaluated using Eqs.(13) and (14) in which standard Heats of Formation are converted to $\Delta \mathrm{H}_{F-C A L}^{0}$, referenced to $\mathrm{T}_{\mathrm{CAL}}$. Conventional "stack losses" may be back-calculated for user convenience. $H P R_{\mathrm{k}}$ is the enthalpy of a non-water product $\mathrm{k}$ at the boundary, including sorbent products for example. Eq.(13) includes water terms, again specified separately for clarity. In Eq.(13): the term $n_{\mathrm{H} 2 \mathrm{O}}$ describes all water found at the boundary, less moisture carried with air leakage $\left(b_{A} \beta\right) ; b_{A}$ is moisture carried with combustion air (relative to $h_{\text {g-CAL }}$ ); $b_{Z}$ describes working fluid leakage air (relative to $\left.\mathrm{h}_{\mathrm{f}-\mathrm{CAL}}\right)$; and by example, the term $\left(\mathrm{n}_{\mathrm{S}-\mathrm{H} 2 \mathrm{O}} \mathrm{z}_{\mathrm{S}}\right)$ describes water products from sorbents (e.g., $\mathrm{CaSO}_{4}$ hydrates) with a required Heat of Association given Eq.(14) would address $H P R_{\text {CaSO4. Eq.(12) is not used, it is }}$ presented for clarity:

$$
\begin{aligned}
& \mathrm{HPR}_{\mathrm{Act}-\mathrm{HHV}}=\mathrm{HPR}_{\mathrm{Ideal}-\mathrm{CM}-\mathrm{HHV}}+\sum(\text { Stack Losses }) / \mathrm{m}_{\mathrm{AF}} \\
& \mathrm{HPR}_{\text {Act-LHV }}=\mathrm{HPR}_{\text {Ideal-CM-LHV }}+\sum(\text { Stack Losses }) / \mathrm{m}_{\mathrm{AF}}
\end{aligned}
$$

$$
\begin{aligned}
& \mathrm{HPR}_{\text {Act-HHV }}=\mathrm{HPR}_{\text {Act-LHV }}=\sum H P R_{\mathrm{k}} \\
& +\left(\mathrm{n}_{\mathrm{H} 2 \mathrm{O}}-\mathrm{b}_{\mathrm{A}}-\mathrm{b}_{\mathrm{Z}}\right)\left(\Delta \mathrm{H}_{g-\mathrm{CAL}-\mathrm{H} 2 \mathrm{O}}^{0}+\mathrm{h}_{\mathrm{Stack}}-\mathrm{h}_{g-\mathrm{CAL}}\right) \\
& +\mathrm{b}_{\mathrm{A}}(1.0+\beta)\left(\Delta \mathrm{H}_{g-\mathrm{CAL}-\mathrm{H} 2 \mathrm{O}}^{0}+\mathrm{h}_{\text {Stack }}-\mathrm{h}_{g-\mathrm{CAL}}\right) \\
& +\mathrm{n}_{\mathrm{S}-\mathrm{H} 2 \mathrm{O}} \mathrm{Z}_{\mathrm{S}}\left(\Delta \mathrm{H}_{g \text {-CAL-H2O }}^{0}+\Delta \mathrm{H}_{A \text {-CAL-CaSO4 }}^{0}+\mathrm{h}_{\mathrm{ESP}}-\mathrm{h}_{g \text {-CAL }}\right) \\
& \left.+\mathrm{b}_{\mathrm{Z}}\left(\Delta \mathrm{H}_{f-\mathrm{CAL}-\mathrm{H} 2 \mathrm{O}}^{0}+\mathrm{h}_{\text {Stack }}-\mathrm{h}_{f-\mathrm{CAL}}\right)\right] /\left(\mathrm{xN}_{\mathrm{AF}}\right)
\end{aligned}
$$

For non-water products:

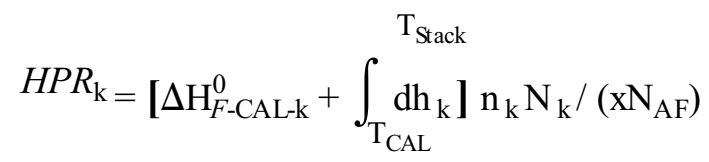

An absorption efficiency, $\eta_{\mathrm{A}}$, based on Eq.(11), is derived from HNSL, whose individual terms are evaluated using established procedures:

$$
\begin{aligned}
\text { HNSL }=\mathrm{L}_{\beta}+\mathrm{L}_{\mathrm{P}}+\mathrm{L}_{\mathrm{d} / \text { Fly }}+\mathrm{L}_{\mathrm{d} / \text { Bott }} \\
+\mathrm{L}_{\mathrm{d} / \mathrm{Sorb}}+\mathrm{L}_{\mathrm{RJ}}-\mathrm{W}_{\mathrm{ID}} / \mathrm{m}_{\mathrm{AF}}
\end{aligned}
$$

HNSL bears the same numerical value for both gross or net calculations, as does $\eta_{\mathrm{A}}$ (see below). All terms of Eq.(15) are specific to unity mass of fuel (i.e., Btu/ $/ \mathrm{bm}_{\mathrm{AF}}$ ). Again, these terms affect product streams, no term can be included which does not have such affect. Slight exceptions to standard usage include the following: $\mathrm{L}_{\beta}$ is referenced to the total gross (corrected) calorific input, (HHVP + HBC), not HHV or LHV; the $\mathrm{L}_{\mathrm{W}}$ term (of PTC 4.1) is combined with the ash pit term $\mathrm{L}_{\mathrm{P}} ; \mathrm{L}_{\mathrm{d} / \text { Fly }}$ is sensible heat in fly ash referenced to its collection point (e.g., the electrostatic precipitator); $\mathrm{L}_{\mathrm{d} / \text { Bott }}$ is the sensible heat in bottom ash, a separate stream from fly ash; $\mathrm{L}_{\mathrm{d} / \mathrm{Sorb}}$ is the sensible heat of Sorbent inert matter referenced to its collection point; and $\mathrm{L}_{\mathrm{RJ}}$ is the fuel rejects term, an outlet stream.

The ID Fan power, $\mathrm{W}_{\mathrm{ID}}$, negatively corrects HNSL such that the fuel's calorimetrics are conserved. So-called "back-pass" components affect the outlet gas stream by changing boundary temperature and thus the correction (negative for a fan). Most standards advise to leave the ID Fan outside the boundary. This is possible provided temperature and emissions measurements are collected before the fan, which is unusual. It is suggested that all gas fans be included, correcting as indicated. One can argue that correcting a stack temperature for the ID Fan $\Delta \mathrm{T}$ does the same thing. Of course for many situations this might be adequate. However, an exception can be quickly be found with high water systems (e.g., given a high water peat or lignite fuel), in which a $10 \Delta^{\mathrm{o}} \mathrm{F}$ correction to stack temperature adds a $0.02 \% \Delta \eta_{\mathrm{B}-\mathrm{LHV}}$ error given the affect of non-linear water properties.

From Eqs.(11A) and (7A) it becomes apparent that the $\eta_{\mathrm{A}}$ term is defined as follows:

$$
\eta_{\mathrm{A}}=1.0-\frac{\mathrm{HNSL}}{-\mathrm{HPR}_{\mathrm{Act}-\mathrm{HHV}}+\mathrm{HRX}_{\mathrm{Act}-\mathrm{HHV}}}
$$

There is subtlety here. For consistency with Eq.(11), $\eta_{\mathrm{A}}$ must be defined in terms of $\mathrm{HPR}_{\text {Act }}$ and $\mathrm{HRX}_{\mathrm{Act}}$ and thus $\eta_{\mathrm{A}}$ becomes a multiplicative affect on boiler efficiency. While this approach minimizes error in $\eta_{\mathrm{B}}$, the individual terms comprising HNSL have the same weight as stack losses (via $\mathrm{HPR}_{\mathrm{Act}}$ ). In terms of boiler efficiency, Eq.(17) then becomes obvious:

$$
\begin{aligned}
& \eta_{\mathrm{B}-\mathrm{HHV}}=\frac{-\mathrm{HPR}_{\text {Act-HHV }}+\mathrm{HRX}_{\text {Act-HHV}}-\eta_{\mathrm{A}}}{\mathrm{HHVP}+\mathrm{HBC}} \\
& \eta_{\mathrm{B}-\mathrm{LHV}}=\frac{-\mathrm{HPR}_{\text {Act-LHV }}+\mathrm{HRX}_{\text {Act-LHV}}-\eta_{\mathrm{A}}}{\text { LHVP }+ \text { HBC }}
\end{aligned}
$$

Note that the "effluent" portion of Eq.(17) is the commonly termed combustion efficiency (i.e., $\eta_{\mathrm{C}}$, thus, for example: $\eta_{\mathrm{B}-\mathrm{HHV}}=\eta_{\mathrm{C}-\mathrm{HHV}} \eta_{\mathrm{A}}$ ).

In summary, all gas/air/working fluid data to the system must be corrected to a common energy level associated with the fuel, $\mathrm{T}_{\mathrm{CAL}}$. Firing Corrections affect reactants, while loss terms correct ideal products - both relative to how these terms were established via a 
specified $\mathbf{T}_{\mathbf{C A L}}$. This is not to say that changes in a Firing Correction might not affect losses; it says that starting from Eq.(4A) lending to Eq.(7), Firing Corrections per se merely balance the calorimetric equation. For the boiler efficiency of Eq.(7), they appear in both numerator and denominator; losses only in the numerator. For ideal combustion, Firing Corrections can not impact efficiency. Without losses, boiler efficiency will always be unity. In the presence of losses, Firing Corrections may impact efficiency but only through the numerics of the efficiency equation. The term HBC is well defined in a previous work (Lang, 2009b).

Air leakage is a fine example of loss effects versus Firing Corrections. If, given an increase in air leakage, Stack temperature is falsely held constant, efficiency will degrade sightly but only because of an increased air flow needed to maintain Boiler $\mathrm{O}_{2}$, but with higher Stack $\mathrm{O}_{2}$ and thus higher losses. However, when lowering Stack temperature reflecting dilution by leakage, one computes a reduction in efficiency.

\section{CALORIFIC CONVERSIONS}

Another inconsistency in industrial standards for boiler efficiency lies when converting from gross to net calorific values, and from a constant volume to a constant pressure process. For example, a constant is many times used to convert from constant volume HHV to the constant pressure HHVP (i.e., the As-Fired). Fuel oxygen is sometimes ignored. Underlying correct procedures, the latent heat at constant volume $\left(\Delta \mathrm{u}_{\mathrm{fg}-\mathrm{CAL}}\right)$ and the latent heat at constant pressure $\left(\Delta \mathrm{h}_{\mathrm{fg}-\mathrm{CAL}}\right)$ at $\mathrm{T}_{\mathrm{CAL}}$ must sever as the bases. To convert solid and liquid fuel calorific heating values from a constant volume to a constant pressure process:

$$
\begin{aligned}
& \mathrm{HHVP}=\mathrm{HHV}+\Delta \mathrm{H}_{\mathrm{V} / \mathrm{P}} \\
& \mathrm{LHVP}=\mathrm{LHV}+\Delta \mathrm{H}_{\mathrm{V} / \mathrm{P}}-\Delta \mathrm{P} \mathrm{V}_{\mathrm{L} / \mathrm{H}} \\
& \Delta \mathrm{H}_{\mathrm{V} / \mathrm{P}}= \mathrm{RT}_{\mathrm{CAL}-\mathrm{Abs}}\left(\alpha_{\mathrm{H} 2} / 2-\alpha_{\mathrm{N} 2}-\alpha_{\mathrm{O} 2}\right) /\left(\mathrm{JN}_{\mathrm{AF}}\right) \\
& \Delta \mathrm{H}_{\mathrm{L} / \mathrm{H}}=\Delta \mathrm{h}_{f g-\mathrm{CAL}-\mathrm{H} 2 \mathrm{O}}\left(\mathrm{n}_{\mathrm{Ideal}-\mathrm{H} 2 \mathrm{O}}\right) \\
&=\Delta \mathrm{h}_{f g-\mathrm{CAL}-\mathrm{H} 2 \mathrm{O}}\left(\alpha_{\mathrm{C}-\mathrm{H}-\mathrm{Gas}} \mathrm{z} / 2+\alpha_{\mathrm{H} 2 \mathrm{O}}\right. \\
&\left.\quad+\alpha_{\mathrm{H} 2}+\alpha_{\mathrm{H} 2 \mathrm{~S}}\right) \mathrm{N}_{\mathrm{H} 2 \mathrm{O}} / \mathrm{N}_{\mathrm{AF}} \\
& \Delta \mathrm{U}_{\mathrm{L} / \mathrm{H}}=\Delta \mathrm{u}_{f g-\mathrm{CAL}-\mathrm{H} 2 \mathrm{O}}\left(\alpha_{\mathrm{C}-\mathrm{H}-\mathrm{Gas}} \mathrm{z} / 2+\alpha_{\mathrm{H} 2 \mathrm{O}}\right. \\
&\left.\quad+\alpha_{\mathrm{H} 2}+\alpha_{\mathrm{H} 2 \mathrm{~S}}\right) \mathrm{N}_{\mathrm{H} 2 \mathrm{O}} / \mathrm{N}_{\mathrm{AF}} \\
& \Delta \mathrm{PV}_{\mathrm{L} / \mathrm{H}}=\Delta \mathrm{H}_{\mathrm{L} / \mathrm{H}}-\Delta \mathrm{U}_{\mathrm{L} / \mathrm{H}}
\end{aligned}
$$

where $\mathrm{T}_{\text {CAL-Abs }}$ is the absolute. Note that the new ASTM D5828-07 standard employs these same relationships under a work order initially prepared by the author, but employing weight fractions. To convert from a gross (higher) to a net (lower) heating value, the following are exact and consistent with the above:

$$
\begin{aligned}
\mathrm{LHV} & =\mathrm{HHV}-\Delta \mathrm{U}_{\mathrm{LH}} \\
\mathrm{LHVP} & =\mathrm{HHVP}-\Delta \mathrm{H}_{\mathrm{LH}}
\end{aligned}
$$

The latent heat of water has obvious import when converting from a gross to a net heating value. Although laboratories typically only report the gross, when a fossil fuel is burned its net energy is liberated. There can be no distinction imposed at the time a fuel is burned commercially versus how its energy was determined in the laboratory. If the calorimetric process were to end midpath, with vaporized water, the derived energy liberated must be the same as would be determined from the completed combustion/vaporization/condensation process. Thus conversion to LHVP serves a useful example. LHVP must employ the $\mathrm{T}_{\mathrm{CAL}}$ reference for conversions, to do otherwise implies capricious thermodynamics: one cannot use one latent heat for entrained water, another for water formed from combustion, and yet another latent heat for air's moisture.

\section{COMPUTED FUEL FLOW, THE ABSOLUTE TEST}

Why does adherence to such thermodynamic consistency matter? Is not any definition of efficiency valid if taken as a relative measure (and more so when using high energy fuels)? If an efficiency test produces a boiler efficiency within 0.5 to $1.0 \%$ of guarantee, such refinement could matter greatly. If the performance engineer computes an emission flow base on a relative or erroneous boiler efficiency, paying more carbon taxes as a result, it could matter greatly. Such financial arguments aside, industrial standards should be relied on for state-ofthe-art methods.

As-Fired fuel flow is not an arbitrary parameter, it is absolute and solely dependent on the fuel's interaction with gas/air/working fluid (i.e., boiler efficiency). If, indeed, such conversion of fuel energy were dependent (say on an air temperature, an arbitrary $25^{\circ} \mathrm{C}$, etc.), then computed fuel flow based on that conversion would be arbitrary. From the Input-Output Method, where $\mathrm{Q}_{\mathrm{WF}}$ is the "Useful Energy Flow Developed" of Eq.(1), fuel flow follows by back-calculation:

$$
\begin{aligned}
& \mathrm{m}_{\mathrm{AF}}=\mathrm{Q}_{\mathrm{WF}} /\left[\eta_{\mathrm{B}-\mathrm{HHV}}(\mathrm{HHVP}+\mathrm{HBC})\right] \\
& \mathrm{m}_{\mathrm{AF}}=\mathrm{Q}_{\mathrm{WF}} /\left[\eta_{\mathrm{B}-\mathrm{LHV}}(\mathrm{LHVP}+\mathrm{HBC})\right]
\end{aligned}
$$

When following the guidelines advocated herein, the same fuel flow will be computed given the same losses, using either gross or net efficiency, at any calorimetric temperature and at any level of Firing Corrections. Fuel flow supplied to an in-situ system, interacting with its gas/air/working fluids, is a fixed quantity; it is what it is it cannot be a function of a user selected reference!! 


\section{IDENTITIES}

From Eq. (26) it is obvious that the ratio $\left[\mathrm{Q}_{\mathrm{WF}} / \mathrm{m}_{\mathrm{AF}}\right]$ is constant, gross and net. Also, from Eq.(11), considering that HNSL and HBC are defined the same for gross and net calculations, the following are developed and considered important identities; see Eq.(16).

$$
\begin{aligned}
\eta_{\mathrm{B}-\mathrm{HHV}}(\mathrm{HHVP} & +\mathrm{HBC}) \equiv \eta_{\mathrm{B}-\mathrm{LHV}}(\mathrm{LHVP}+\mathrm{HBC}) \\
-\mathrm{HPR}_{\text {Act-HHV }} & +\mathrm{HRX}_{\text {Act-HHV }} \\
& \equiv-\mathrm{HPR}_{\text {Act-LHV }}+\mathrm{HRX}_{\text {Act-LHV }}
\end{aligned}
$$

When taking individual stream energies in isolation, the product term becomes irrelevant to gross or net bases as seen in Eq.(13). However, this is also the case for the reactant term given comparison of Eqs.(4B3) and (4C3), and in light of Eq.(25), that:

$$
\begin{gathered}
\mathrm{HHVP}+\left(\mathrm{n}_{\text {Ideal-H2O }} \Delta \mathrm{H}_{f \text {-Cal-H2O }}^{0}\right) /\left(\mathrm{xN}_{\mathrm{AF}}\right)= \\
\mathrm{LHVP}+\left(\mathrm{n}_{\text {Ideal-H2O }} \Delta \mathrm{H}_{g-\text { Cal-H2O }}^{0}\right) /\left(\mathrm{xN}_{\mathrm{AF}}\right)
\end{gathered}
$$

Thus, as treatment of boundary streams must be divorced from gross or net assumptions, the actual Enthalpy of Product, and Enthalpy of Reactant terms must be identical:

$$
\begin{aligned}
\mathrm{HPR}_{\text {Act-HHV }} & \equiv \mathrm{HPR}_{\text {Act-LHV }} \\
\operatorname{HRX}_{\text {Act-HHV }} & \equiv \mathrm{HRX}_{\text {Act-LHV }}
\end{aligned}
$$

\section{SENSITIVITY TO PROPERTIES}

Many would argue that methods of any stripe - be they consistent or tolerated for convenience - are viable if producing "acceptable errors". However, the problem in agreeing with the notion of an acceptable error is that our responsibility as engineers when writing standards should be to produce state-of-the-art procedures based on sound thermodynamics, one can never anticipate how a standard might be used.

These things said, methods addressing consistent calorimetrics are not needed if testing systems using fuels producing little water on combustion. It is of interest that ASME PTC 4.1 whose pedigree runs back to 1964, with foundations in the Babcock \& Wilcox's Heat Loss Method (taking off another 50 years!), addressed an era in which high energy coal predominated in the U.S.

The source of conceptual calorimetric errors for high product water fuels lies with the sensitivity of the latent heat of water, and its Heat of Formation of the liquid, to temperature as seen in Tables $1 \mathrm{~A} \&$ \& $1 \mathrm{~B}$. The temperature dependency for water's latent heat is great indicating a $1 \%$ sensitivity for every $18 \Delta^{\circ} \mathrm{F}\left(10 \Delta^{\circ} \mathrm{C}\right)$. As seen in Table 2 the $\mathrm{SO}_{2}$ sensitivity is slight, while $\mathrm{CO}_{2}$ is 10 times less sensitive than $\mathrm{SO}_{2}$. For fuels with high water contents, the latent heat has obvious import when condensing vapor.

It could be argued that a fossil fuel having low hydrogen but high fuel water has little sensitivity to calorimetric temperature if the bomb's starting and ending temperature is the same. Under the preceding scenario, could the CV be change? Or, if burning pure graphite in a bomb, if the starting and ending temperature is the same, could the CV be change? The answer is that the CV may very well change due to the path chosen for Eq.(2). By way of example, let's assume that graphite's CV is being measured in a calorimeter capable of variable bath temperature. If the bomb is started at $77^{\circ} \mathrm{F}$, then reduced to $34^{\circ} \mathrm{F}$ where the graphite is burned, then assume a return to $77^{\circ} \mathrm{F}$ - even taking zero change in $\Delta \mathrm{H}_{F-\mathrm{CO} 2}^{0}$ - changes reflected in the heat capacity of graphite going to $34^{\circ} \mathrm{F}$, and the heat capacity of $\mathrm{CO}_{2}$ coming from $34^{\circ} \mathrm{F}$, are different resulting in an observed $\mathrm{CV}$ which must be different from $\Delta \mathrm{H}_{F-\mathrm{CO} 2}^{0}$ at $77^{\circ} \mathrm{F}$. If water is added to the graphite, path dependency becomes even more obvious. Of course traditional bombs are run with constant temperature in pure $\mathrm{O}_{2}$, and since Eq.(2), and thus Eq.(4A), etc. are path dependent ... we must simply adhere to how the process was run!

The ideal product of combustion, $\mathrm{HPR}_{\text {Ideal-CF, is }}$ defined by the Heats of Formation of the comprising ideal products of: $\Delta \mathrm{H}_{F-\mathrm{CAL}-\mathrm{CO} 2}^{0}, \quad \Delta \mathrm{H}_{F-\mathrm{CAL}-\mathrm{SO} 2}^{0}$, and $\Delta \mathrm{H}_{f-\mathrm{CAL}-\mathrm{H} 2 \mathrm{O}}^{0}$ or $\Delta \mathrm{H}_{g-\mathrm{CAL}-\mathrm{H} 2 \mathrm{O}}^{0}$ The sensitivity of these terms is reflected in the ratio $\left(\Delta \mathrm{HPR}_{\text {Ideal-CF }} / \mathrm{HPR}_{\text {Ideal-CF }}\right)$ per $1.0 \Delta^{\circ} \mathrm{C}$ as presented in Table 3 for all Ranks of coal. Note that the indicated arrow points to the hvBb Rank fuel (and to those below) whose associated efficiencies can be sufficiently affected by a $\Delta \mathrm{H}_{F-C A L}^{0}$ change due to a change in reference temperature. Sensitivity of the $\left(\Delta \mathrm{HPR}_{\text {Ideal-CF }} / \mathrm{HPR}_{\text {Ideal-CF }}\right)$ term explains why efficiencies associated with the poor quality fuels, having very high product water, have greater sensitivity to $\mathrm{T}_{\mathrm{CAL}}$, and concomitantly have reduced uncertainty versus high energy fuels. Of course this apparent paradox is explained by recognizing the nature of thermochemical properties. Applied thermodynamics of calorimetrics suggests an interesting ambivalence associated with the Energy Balance Method.

When reckoning the insensitivity of $\mathrm{CO}_{2}$, and that seen in Table 3, consider an example of burning pure graphite in a constant temperature bomb. Again let us turn to determining graphite's CV, not through known Heats of Formation, but rather using a bomb calorimeter. Using results from our graphite calorimeter, one would compute a Energy Balance efficiency which is essentially devoid of temperature dependency. What does it mean then having a system which produces no water and whose Heat of Combustion is insensitive to temperature? Eq.(7) will produce different boiler efficiencies based on any chosen calorimetric bath temperature, using essentially the same $\mathrm{CV}$, but producing a variable fuel flow given "arbitrary" Firing Corrections. Does this imply that our thermo- 
dynamic understanding of a graphite system is impossible? No, however it does mean that methods akin to the Energy Balance Method of Eq.(7), are crippled by the nature of thermochemical properties and our inability to discern Heats of Combustion to the accuracy required.

Simply put, the Energy Balance (Heat Loss) Method has limitations. Table 3 inherently suggests that a lower limit of $10 \%$ by weight of fuel water plus fuel hydrogen be placed on the applicability of the Energy Balance Method.

However, if forced to use an Input-Output approach for low product water fuels, we still have the problem of viable Firing Corrections procedures. For the situation of a fuel having $<10 \%$ water plus hydrogen, it is proposed to place an error bound on the Input-Output determined boiler efficiency which is dependent on the sensitivity an agreed temperature range has on the Firing Corrections, and thus on boiler efficiency.

Tables 4, 5 and 6 illustrate effects on methane and several coal fuels given a $18 \Delta^{\circ} \mathrm{F}\left(10 \Delta^{\circ} \mathrm{C}\right)$ change, a misuse, in calorimetric temperature. As seen, differences range from 0.4 to $0.8 \%$ in efficiency. The difference between running a bomb at $95^{\circ} \mathrm{F}$ versus $77^{\circ} \mathrm{F}$ is not considered uncommon. Nor is it uncommon to compute methane's CV at $60^{\circ} \mathrm{F}$, but then use a $77^{\circ} \mathrm{F}$ reference. Note that these are only a portion of the conceptual errors. When mis-using loss or "credit" terms, errors have been observed to exceed an additional $1 \%$ to $2 \%$ in $\Delta \eta_{\mathrm{B}}$ (depending on vendor practices and manipulations of standards).

Table 1A: Sensitivities of Water's Saturated Energies at Constant Pressure

\begin{tabular}{||c||c|c||c|c||c|c||}
\hline $\begin{array}{c}\text { Reference } \\
\text { Temp. }\end{array}$ & $\begin{array}{c}\text { Enthalpy, } \\
\text { Sat. Liquid } \\
(\mathrm{Btu} / \mathrm{lbm})\end{array}$ & $\begin{array}{c}\text { Change } \\
(\%)\end{array}$ & $\begin{array}{c}\text { Enthalpy, } \\
\text { Sat. Vapor } \\
(\mathrm{Btu} / \mathrm{lbm})\end{array}$ & $\begin{array}{c}\text { Change } \\
(\%)\end{array}$ & $\begin{array}{c}\text { Latent Heat } \\
\text { for Water } \\
(\Delta \mathrm{Btu} / \mathrm{lbm})\end{array}$ & $\begin{array}{c}\text { Change } \\
(\%)\end{array}$ \\
\hline \hline $25^{\circ} \mathrm{C}\left(77^{\circ} \mathrm{F}\right)$ & 45.093 & 0.000 & 1095.094 & 0.000 & 1050.001 & 0.000 \\
\hline $30^{\circ} \mathrm{C}\left(86^{\circ} \mathrm{F}\right)$ & 54.080 & +19.93 & 1098.996 & +0.356 & 1044.916 & -0.487 \\
\hline $35^{\circ} \mathrm{C}\left(95^{\circ} \mathrm{F}\right)$ & 63.061 & +39.99 & 1102.879 & +0.711 & 1039.818 & -0.979 \\
\hline
\end{tabular}

Table 1B: Sensitivities of Water's Heat of Formation

\begin{tabular}{||c||c|c||c|c|}
\hline $\begin{array}{c}\text { Reference } \\
\text { Temp. }\end{array}$ & $\begin{array}{c}\mathrm{H}_{2} \mathrm{O} \text { Heat of } \\
\text { Formation } \\
\text { LiQ } \\
(\mathrm{Btu} / \mathrm{lbm})\end{array}$ & $\begin{array}{c}\text { PerCent } \\
\text { Change } \\
(\%)\end{array}$ & $\begin{array}{c}\mathrm{H}_{2} \mathrm{O} \text { Heat of } \\
\text { Formation } \\
\text { VAP } \\
(\mathrm{Btu} / \mathrm{lbm})\end{array}$ & $\begin{array}{c}\text { Change } \\
(\%)\end{array}$ \\
\hline \hline $25^{\circ} \mathrm{C}\left(77^{\circ} \mathrm{F}\right)$ & -6821.142 & 0.0000 & -5771.140 & 0.000 \\
\hline $30^{\circ} \mathrm{C}\left(86^{\circ} \mathrm{F}\right)$ & -6817.358 & -0.0555 & -5772.442 & +0.023 \\
\hline $35^{\circ} \mathrm{C}\left(95^{\circ} \mathrm{F}\right)$ & -6813.584 & -0.1109 & -5773.766 & +0.046 \\
\hline
\end{tabular}

Table 2: Sensitivities of $\mathrm{SO}_{2}$ Heat of Formation

\begin{tabular}{||c||c|c||}
\hline $\begin{array}{c}\text { Reference } \\
\text { Temp. }\end{array}$ & $\begin{array}{c}\mathrm{SO}_{2} \text { Heat of Formation } \\
(\mathrm{Btu} / \mathrm{lbm})\end{array}$ & $\begin{array}{c}\text { Change } \\
(\%)\end{array}$ \\
\hline \hline $25^{\circ} \mathrm{C}\left(77^{\circ} \mathrm{F}\right)$ & -1992.0031 & 0.0000 \\
\hline $30^{\circ} \mathrm{C}\left(86^{\circ} \mathrm{F}\right)$ & -1992.1867 & 0.0092 \\
\hline $35^{\circ} \mathrm{C}\left(95^{\circ} \mathrm{F}\right)$ & -1992.3670 & 0.0183 \\
\hline
\end{tabular}

Table 4: Calorimetric Temperature Affects on a Methane System Given an $18 \Delta^{0} \mathrm{~F}$ Mis-Use of Calorimetric Temperature

\begin{tabular}{|c||c|c|c||}
\hline $\begin{array}{c}\text { Computed CV } \\
\text { for Methane }\end{array}$ & $\begin{array}{c}\text { Gross Efficiency } \\
\text { Calculated at } 60^{\circ} \mathrm{F}\end{array}$ & $\begin{array}{c}\text { Gross Efficiency } \\
\text { Calculated at } 78^{\circ} \mathrm{F}\end{array}$ & $\begin{array}{c}\text { All Terms } f\left(\mathrm{~T}_{\mathrm{CAL}}\right) \\
\text { affecting } \Delta \eta_{\mathrm{B}-\mathrm{HHV}}\end{array}$ \\
\hline \hline 23891.00 at $60^{\circ} \mathrm{F}$ & $82.348 \%$ (actual) & $82.825 \%$ & $0.477 \%$ \\
\hline 23865.92 at $78^{\circ} \mathrm{F}$ & $82.330 \%$ & $82.807 \%$ (actual) & $0.477 \%$ \\
\hline
\end{tabular}


Table 3: As-Received (wet) Properties of Fossil Fuels (data from Penn. State, Input/Loss installations \& NIST)

\begin{tabular}{|c|c|c|c|c|c|c|c|}
\hline $\begin{array}{c}\text { Substance } \\
\text { or Coal Rank }\end{array}$ & $\begin{array}{c}\text { Fuel } \\
\text { Hydrogen } \\
(\% \mathrm{wt})\end{array}$ & $\begin{array}{c}\text { Fuel } \\
\text { Water } \\
(\% \mathrm{wt})\end{array}$ & $\begin{array}{l}\text { Combined } \\
\mathrm{H}_{2} \& \mathrm{H}_{2} \mathrm{O} \\
(\% \mathrm{wt})\end{array}$ & $\begin{array}{l}\text { Fuel } \\
\text { Ash } \\
(\% \mathrm{wt})\end{array}$ & $\begin{array}{l}\text { Avg. HHV } \\
\text { at } 25^{\circ} \mathrm{C} \\
(\mathrm{Btu} / \mathrm{lbm})\end{array}$ & $\begin{array}{c}\text { HHV } \\
\text { Temp.Coef. } \\
\left(\times 10^{-6} / 1 \Delta^{\circ} \mathrm{C}\right)\end{array}$ & $\frac{\Delta \mathrm{HPR}_{\text {Ideal-CF}}}{\mathrm{HPR}_{\text {Ideal-CF }}}$ \\
\hline an & 1.94 & 3.55 & 5.49 & 9.85 & 12799.75 & 19.56 & 376.6 \\
\hline $\mathrm{sa}$ & 3.01 & 1.44 & 4.70 & 16.51 & 12466.17 & 30.10 & 285.0 \\
\hline lvb & 3.97 & 1.69 & 5.66 & 13.22 & 13155.11 & 39.22 & 347.7 \\
\hline mvb & 4.44 & 1.75 & 6.19 & 11.48 & 13371.75 & 41.88 & 380.5 \\
\hline Benzoic Acid & 4.95 & 0.00 & 4.95 & 0.00 & 11364.57 & 45.0 (NIST) & --- \\
\hline hvAb & 4.91 & 2.39 & 7.30 & 10.86 & 13031.61 & 47.77 & 444.2 \\
\hline $\mathrm{hvBb}$ & 4.63 & 5.61 & 10.24 & 11.83 & 11852.63 & 56.53 & $446.7 \leftarrow$ \\
\hline $\mathrm{hvCb}$ & 4.26 & 9.89 & 9.87 & 12.32 & 10720.40 & 60.18 & 450.6 \\
\hline subA & 3.94 & 12.93 & 16.87 & 7.06 & 10292.89 & 51.16 & 398.3 \\
\hline subB & 3.76 & 17.87 & 21.63 & 9.57 & 9259.75 & 61.15 & 408.0 \\
\hline subC & 3.50 & 23.79 & 27.29 & 10.67 & 8168.69 & 75.14 & 423.3 \\
\hline $\operatorname{lig} \mathrm{A}$ & 3.02 & 29.83 & 32.81 & 9.64 & 7294.66 & 83.56 & 439.4 \\
\hline Methane & 25.33 & 0.00 & 25.33 & 0.00 & 23867.31 & 105.39 & 424.3 \\
\hline Irish Peat & 2.73 & 46.78 & 49.51 & 1.72 & 4856.07 & 112.00 (est.) & 542.7 \\
\hline ligB-PSU & 2.16 & 28.84 & 31.00 & 22.95 & 4751.83 & 122.17 & 481.3 \\
\hline ligB-Greek & 1.39 & 54.04 & 55.43 & 16.93 & 2926.82 & 246.01 & 685.2 \\
\hline
\end{tabular}

Table 5: Effects on Gross Boiler Efficiency Given an $18 \Delta^{\mathbf{0}} \mathrm{F}$ Mis-Use of Calorimetric Temp.

\begin{tabular}{||c||c|c|c||}
\hline Unit & $\mathrm{T}_{\mathrm{CAL}}=77^{\circ} \mathrm{F}$ & $\mathrm{T}_{\mathrm{CAL}}=95^{\circ} \mathrm{F}$ & $\Delta \eta_{\mathrm{B}-\mathrm{HHV}}$ \\
\hline \hline $\begin{array}{c}\text { 110 MWe, CFB, } \\
\text { Bituminous Coal Waste }\end{array}$ & $87.678 \%$ & $88.165 \%$ & $0.487 \%$ \\
\hline $\begin{array}{c}800 \text { MWe Coal Slurry } \\
\text { with Gas Over-Fire }\end{array}$ & $81.174 \%$ & $81.722 \%$ & $0.548 \%$ \\
\hline
\end{tabular}

Table 6: Effects on Gross \& Net Boiler Efficiencies Given an $18 \Delta^{0} \mathrm{~F}$ Mis-Use of Calorimetric Temperature

\begin{tabular}{||c||c|c|c|c||}
\hline Unit & $\mathrm{T}_{\mathrm{CAL}}=77^{\circ} \mathrm{F}$ & $\mathrm{T}_{\mathrm{CAL}}=95^{\circ} \mathrm{F}$ & $\Delta \eta_{\mathrm{B}-\mathrm{HHV}}$ & $\Delta \eta_{\mathrm{B}-\mathrm{LHV}}$ \\
\hline \hline $\begin{array}{c}600 \mathrm{MWe} \text { PRB Coal, } \\
\mathrm{HHV}=8542.828 \mathrm{Btu} / \mathrm{lbm}\end{array}$ & $83.602 \%$ & $84.117 \%$ & $0.515 \%$ & \\
\hline $\begin{array}{c}600 \mathrm{MWe} \text { PRB Coal, } \\
\text { LHV = 7958.786 Btu/lbm }\end{array}$ & $90.127 \%$ & $90.646 \%$ & & $0.519 \%$ \\
\hline \hline $\begin{array}{c}300 \mathrm{MWe} \text { Lignite-B, } \\
\mathrm{HHV}=3369.499 \mathrm{Btu} / \mathrm{lbm}\end{array}$ & $68.395 \%$ & $69.036 \%$ & $0.641 \%$ & \\
\hline $\begin{array}{c}300 \mathrm{MWe} \text { Lignite-B, } \\
\text { LHV }=2760.249 \mathrm{Btu} / \mathrm{lbm}\end{array}$ & $85.047 \%$ & $85.761 \%$ & & $0.714 \%$ \\
\hline \hline
\end{tabular}


Table 7: Numeric Overchecks Using EX-FOSS

\begin{tabular}{||l||c|c||c|c||}
\hline \multicolumn{1}{||l||}{ Case } & Boiler Eff, Eq.(17) $\%$ & \multicolumn{2}{|c||}{ Fuel Flow, Eq.(26), lb/hr } \\
\cline { 2 - 5 } & HHV & LHV & HHV & LHV \\
\hline \hline Boardman System Evaluation Test, Case SET-Data_Master & 84.616 & 91.688 & $665,418.39$ & $665,418.40$ \\
\hline Boardman DSI Testing: Sodium Bicarbonate, Case $\mathrm{G}$ & 85.627 & 92.255 & $651,387.35$ & $651,387.40$ \\
\hline Graphite Fuel, no losses, $\mathrm{T}_{\mathrm{CAL}}=\mathrm{T}_{\mathrm{RA}}=\mathrm{T}_{\text {Stack }}=77.0^{\circ} \mathrm{F}$ & 85.259 & 91.981 & $652,061.39$ & $652,061.36$ \\
\hline Graphite Fuel, no losses, $\mathrm{T}_{\mathrm{CAL}}=\mathrm{T}_{\mathrm{RA}}=\mathrm{T}_{\text {Stack }}=39.0^{\circ} \mathrm{F}$ & 100.00 & 100.00 & $174,114.02$ & $174,114.02$ \\
\hline Graphite Fuel, dry air, $\mathrm{T}_{\mathrm{CAL}}=39.0^{\circ} \mathrm{F}, \mathrm{T}_{\mathrm{RA}}=\mathrm{T}_{\text {Stack }}=77.0^{\circ} \mathrm{F}$ & 98.138 & 98.138 & $174,100.33$ & $174,100.33$ \\
\hline PRB Fuel, SET Relative Humidity $=0.0 \%, \mathrm{~T}_{\text {Stack }}=278.900^{\circ} \mathrm{F}$ & 84.665 & 91.742 & $665,030.08$ & $665,030.10$ \\
\hline PRB Fuel, SET Relative Humidity $=100 \%, \mathrm{~T}_{\text {Stack }}=278.900^{\circ} \mathrm{F}$ & 84.611 & 91.683 & $665,457.00$ & $665,457.01$ \\
\hline PRB Fuel, SET Relative Humidity $=100 \%, \mathrm{~T}_{\text {Stack }}=277.155^{\circ} \mathrm{F}$ & 84.665 & 91.742 & $665,030.05$ & $665,030.06$ \\
\hline \hline
\end{tabular}

\section{SENSITIVITY TO NUMERICS}

Although the author would argue that foundations of Input/Loss Method presented in this work are straightforward (especially with Rev. 30 changes), given the stoichiometric complexity of coal-fired systems, computational over-checks are mandated. An excellent overcheck is to compare Eq.(26A) vs. (26B). Another method of controlling errors is to create a mathematical kernel; for Input/Loss it would consist of Eqs.(4B3), (4C3), (13), (14), (15), HBC calcs, and finally (11), with imbedded properties. Of course basic overchecks should be applied using all standards. Table 7 presents a sampling of EX-FOSS overchecks (Lang, 2012a) for a variety of systems, with and without losses, using different $\mathrm{T}_{\mathrm{CAL}}$ and reactant conditions; note the matching of fuel flows, HHV versus LHV. For each given case, Firing Corrections $(\mathrm{HBC})$ and $\eta_{\mathrm{A}}$ were computed identically.

Table 7's last three cases illustrate that although reactant conditions cannot affect ideal combustion, increasing product moisture given a fogged combustion air, while holding $\mathrm{T}_{\text {Stack }}$ constant, causes higher losses; the process must add heat to bring the air's moisture to the same $\mathrm{T}_{\text {Stack }}$; Stack cooling has been ignored. However, when $T_{\text {Stack }}$ is decreased to exactly address such cooling, no change in efficiency or fuel flow is observed.

\section{ASME VERSUS THE WORLD}

In North America the gross (higher) heating value based boiler efficiency is the norm for conventional steam generators. In the rest of the world, the net (lower) heating value based efficiency is exclusively used. Net efficiencies are higher numerically. Although for the same fuel, small changes in $T_{C A L}$ have a linear effect on $\Delta \eta_{B}$, the affects on $\eta_{B}$ of changes in product water are quite non-linear. For PRB coals, the $\Delta \eta_{B}$ impact is approximately the same between gross and net. Note that Table 6 indicates that for very high product water fuels this conclusion breaks down. Although fuel flows will (and must) compute identically for the same $\mathrm{T}_{\mathrm{CAL}}$ between gross and net, there is numerical subtlety. As $\eta_{\mathrm{B}-\mathrm{LHV}}$ has the higher value, the percent change of a given $\Delta \eta_{\mathrm{B}-\mathrm{LHV}}$ is, of course, less versus a percent change in $\Delta \eta_{\mathrm{B}-\mathrm{HHV}}$. This condition also implies that the computed fuel flow of Eq.(26B) will be slightly less sensitive to mis-use of $\mathrm{T}_{\mathrm{CAL}}$, test uncertainties, etc. The numerical situation implies that greater scrutiny must be given to net-based efficiencies.

\section{SUMMARY AND RECOMMENDATIONS}

A consistent boiler efficiency will result if only considering the fuel's interaction with the gas/air/working fluids, an efficiency leading to a unique fuel flow. Without following such principles, errors can exceed $2 \%$ which may have serious effects on power plant monitoring and economics.

The established standards for computing boiler efficiency require improvement. Conceptual errors occur when not adapting the fundamental process of how the energy content of a fossil fuel is determined. In addition, 
conceptual errors are made in the treatment of major steam generator components.

It is the opinion of the author that standards need to recognize the repeatability accuracy of the modern bomb calorimeter and, in general, should strive for $\pm 0.1 \% \Delta \eta_{\mathrm{B}}$ resolution. The following recommendations, not listed by importance, are offered for consideration when preparing future revisions of the standards.

1) Boiler efficiency standards should publish, as integral to their documentation, data sets which can be replicated by the analyst. Such data sets should begin with a simple combustion system, with one heat exchanger, allowing base thermodynamics to be confirmed and fuel flow computed, followed by increasing complexity leading to the use of sorbents, tube leakages, extreme environments, etc.

2) Boiler efficiency standards should be required to report the reference temperature used in their computations. This should be the temperature at which the fuel's calorific value was determined. If required to employ a specified reference temperature, then the coal-fired operator should specify to the laboratory its desired $\mathrm{T}_{\mathrm{CAL}}$.

3) Calorimetric standards such as ASTM D5865 and ISO 1928:1995(E) should require routine reporting of calorimetric temperatures. This author, sitting on the D5865 committee, was defeated in getting approval of this requirement (his Work Item WK5174 was approved by 66 members, with one negative vote resulting in no modification).

4) Boiler efficiency standards must specify the correct (and consistent) formula for gross to net, \& volume to pressure conversions, all $\mathrm{T}_{\mathrm{CAL}}$ dependent.

5) Standards should specify that any common steam generator component which was included within the system boundary (as defined herein), should be reported and its use fully justified.

6A) Standard committees should investigate the new NASA combustion gas properties which appear to have a wider range than the older JANAF tables (McBride, 2002). For their 2002 publication gas properties are remarkably consistent with AGA and CODATA standards. However, there appears to be some inconsistencies in non-2002 editions such as NASA's on-line CEA (Chemical Equilibrium with Application) data set. All properties should be normalize to the CODATA standard (Cox, 1989).
6B) It is advised to use water properties based on work by Keenan, Keyes, Hill and Moore (1969), later modified by NASA (1973); it represents a truly consistent and continuous surface fit, resulting in an excellent matching to international standards.

7) Boiler efficiency standards must anticipate use of computers and issue approved source coding (preferably in the simplest of FORTRAN, as was done for ASME PTC 22).

8) Consistent application should be made of Enthalpy of Product and Reactant terms as based on the calorimetric process. At the minimum, the latent heat and the Heat of Formation for water must be computed as a function of calorimetric temperature. All chemistry products should be considered when enfolding Stack loss terms into a single formulation. Thus Eq.(13), and a form of Eq.(14), should be employed thus reducing inconsistencies.

9) For solid and liquid fossil fuels, boiler and calorimetric standards must not allow corrections made to as-tested calorific values (other than conventional conversions from gross to net, etc.). Such changes to reference temperatures are allowed under DIN 1942 and are wrong. Laboratory results based on an as-received sample (HHV) must stand as-is and be reported, and used uncorrected.

10) Steam generator standards must strictly adhere to the principle that boiler efficiency can only be degraded by losses applied to outlet streams. Firing Corrections are only applied to inlet streams.

11) Modern boiler efficiency standards should allow for a variable concentration of ambient oxygen. Such variability was common in older standards, and was used in test procedures before 1970. Ambient oxygen is a sensitive parameter for all combustion equations, fixing this value is ill-advised.

12) The Energy Balance (Heat Loss) Method:

a) should be the only method allowed provided fuel water plus fuel hydrogen is $\geq 10 \%$ by weight;

b) evaluations must require the ref. temperature be equal to the calorimetric temperature;

c) should invoke a tolerance statement on efficiency based solely on fuel sampling (CV testing) and those quantities affecting the $\mathrm{Q}_{\mathrm{WF}}$ term; and

d) efficiency should be used to back-calculate fuel flow based on $\mathrm{Q}_{\mathrm{WF}}$ (from the Input-Output definition) for comparison with the actual whenever practical and as agreed between parties. 
13) The Input-Output Method:

a) should only be applied if fuel water plus fuel hydrogen is less than $10 \%$ by weight;

b) should use an agreed reference temperature; and

c) should invoke a tolerance statement on efficiency based on: fuel sampling (CV testing); quantities affecting $\mathrm{Q}_{\mathrm{WF}}$; and affects on Firing Correction given an agreed spread in reference temperature.

14) It is recommended that standards provide easily understood procedures for uncertainty statements affecting principally fuel sampling and $\mathrm{Q}_{\mathrm{WF}}$.

15) As ASME PTC 4 is extremely well-detailed, addressing numerous and important testing practices, it is recommended that it serve, after correction of conceptual and procedural errors, as the basis for re-writing European standards.

16) For all ASME standards which determine thermal efficiency, it is recommended that consistent thermodynamic methods and properties be used. Properties would include: molecular weights, air psychrometrics, water properties, gas properties, Heats of Formulation, air's molar constituents, etc.

\section{NOTES and ERRATA}

The following offers historical notes and errata regards this and related works.

Based on numerous comments by colleagues, several minor revisions were made from the original publication in July 2009, through mid-2010; these ending with Rev. 28B.

Starting in November 2010, a formal comparison was made between the methods discussed here and ASME PTC 4 using test data obtained from the 620 MWe coal-fired Boardman unit (operated by Portland General Electric). The initial analyses were reported at the 2011 ASME Power Conference, POWER2011-55215. This testing work resulted in clarifications to this paper, its Revision 29. As reported to the Conference, the Input/Loss analysis did not employ the HPR $\mathrm{Ideal-CM}_{\text {and } \mathrm{HRX}}$ CAL-CM concepts.

The August 17, 2012 revision (this Rev. 30) represents numerous changes including: 1) a conceptual correction to the base foundation of Input/Loss with changes in nomenclature; 2) adding properties associated with sorbents and their products (Lang, 2012b); 3) use of NASA combustion properties (McBride, 2002); and 4) conversion to Windows 7 with general coding review. Although the conceptual correction resulting in Eq.(4A) added clarity, changes in PRB-fired efficiencies were typically $-0.050 \% \Delta \eta_{\mathrm{B}-\mathrm{HHV}}$ (Rev. 30 being lower). Conceptual corrections also resulted in the identities of Eqs.(30) \& (31). Other corrections resulted in $\pm 0.050 \%$ to $\pm 0.100 \% \Delta \eta_{\mathrm{B}-\mathrm{HHV}}$.

\section{ACKNOWLEDGMENTS}

The author is grateful to his colleagues in Europe and North America, especially ASME reviewers, for their numerous comments and suggestions made on this paper and related parent works. He is grateful for the many questions, and encouragement to publish, originating from China's engineers regarding parent works. He is grateful to Mr. Dimitrios N. Konidaris, Public Power Corporation of Greece, for his detailed review of EX-FOSS and CV conversion techniques, and his suggestions on improved properties. He is grateful to Mr. David Rodgers, Portland General Electric, for his steadfast encouragement and managerial grace, and for use of Boardman's test data. Most especially, he would like to thank Mr. Tom Canning (TCanning@TCD.ie), Trinity College, Dublin and formerly with the Electricity Supply Board, Republic of Ireland, for many long hours of discussions and his many critical reviews. The author also gratefully acknowledges his American Society of Mechanical Engineers for allowing his ASME papers to be made available at www.ExergeticSystems.com, they may be downloaded only for personal use.

\section{REFERENCES}

"Acceptance Testing of Steam Generators", DIN 1942: February 1994, DIN Deutsches Institut für Normung e.V., Berlin; a defunct German standard.

"Code for Acceptance Tests on Stationary Steam Generators of the Power Station Type", BS 2885:1974 (also: ISBN: 058008136 2); a defunct British Standard.

Cox JD, Wagman DD and Medvedev VA, CODATA Key Values for Thermodynamics, Hemisphere Publishing, New York, 1989.

"Fired Steam Generators", Performance Test Code

4: 2008, ASME, New York, NY; the US std. since 1998.

"Gas Turbine Power Plants", Performance Test

Code 22: 1985, ASME, New York, NY.

"Gross Heating Value of Black Liquor", TAPPI, Norcross, Georgia, USA, T684 om-02; published 2002.

Hendricks RC, Peller IC and Baron AK, "WASP-A Flexible FORTRAN IV Computer Code for Calculating Water and Steam Properties", NASA TN-D-7391, 1973.

Keenan JH, Thermodynamics, Wiley \& Sons, New

York: 1941; Chapter XVII.

Keenan JH, Keyes FG, Hill PG, and Moore JG, Steam Tables, John Wiley \& Sons, Inc., NY, 1969.

Kent W, "Rules for Conducting Boiler Tests", ASME 1884 Transactions, pp.260-281, see FIG.66.

Lang FD and Canning T, "An Oxy-Hydrocarbon Model of Fossil Fuels", ASME, 2007 Power Conference, Pwr2007-22007, San Antonio, Texas, 2007.

Lang FD, "Discord in Boiler Efficiency Standards and Calorimetric Temperature (a supplement to the 'Part III Input/Loss Paper')", an 2009a unpublished paper. 
Lang FD, "Monitoring and Improving Coal-Fired Power Plants Using the Input/Loss Method - Part III", ASME, 2000 International Joint Power Conference, IJPGC2000-15079, Miami Beach, FL; a 2009b revision reflecting years of comments and corrections (see its Notes \& Errata).

Lang FD, Golightly T, Rodgers DAT and Canning $\mathrm{T}$, "Effects on Boiler Efficiency Standards of Pulverizing Coal", ASME, 2011 Power Conference, POWER2011-55216, Denver, Colorado, 2011.

Lang FD, EX-FOSS: A Program for Monitoring \& Analysis of Fossil-Fired Boilers, Exergetic Systems, Inc., San Rafael, CA. (June 2012a, Ver.2.8, Mod.40, first published 1983).

Lang FD, "Sorbent Thermodynamic Properties Developed for Portland General Electric", Exergetic Systems, July 2012b; see www.ExergeticSystems.com. McBride BJ, Michael J, Zehe MJ and Gordon S, "Thermodynamic Properties of Individual Species", NASA/TP-2002-211556, September 2002, Glenn Research Center, Cleveland, Ohio.

"Natural gas - Calculation of Compression Factor -

Part 3", ISO 12213-3:2006.

"Natural gas - Standard Reference Conditions",

ISO 13443:1996/Cor 1:1997.

"Orifice Metering of Natural Gas and Other Related

Hydrocarbon Fluids", American Gas Association

(AGA), Report No. 3, September 1985.

"Performance Test Procedure Sodium Based

Recovery Units", CA Report No. 84041601, TAPPI, 1996, TAPPI Press, Atlanta, GA. Also see "Recovery Boiler Performance Calculation - Short Form", TIP 0416-01, 2001, TAPPI Press, Atlanta, GA.

"Solid Mineral Fuels - Determination of Gross Calorific Value by the Bomb Calorimetric Method, and Calculation of Net Calorific Value”, ISO 1928:1995(E).
"Standard Test Method for Gross Calorific Value of Coal and Coke", ASTM D5865-04, ASTM, 2005.

"Steam Generating Units", Power Test Code 4.1: 1964, 1973 (Reaffirmed 1991), ASME, New York, NY; a defunct U.S. standard.

U.S. Patent 6584429 was issued June 24, 2003.

This patent is owned by the author's company and, upon written request, will be made available for ASME's use without royalties; use outside the U.S. requires no request.

U.S. Standard Atmosphere, 1976, NASA-TM-X74335, U.S. Gov. Printing Office, Wash. DC, 1976.

Vakkilainen EK and Ahtila P, "Modern Method to Determine Recovery Boiler Efficiency", 2009 TAPPI Engg., Pulping, Environmental Conference", from: www.tappi.org/Bookstore/Technical-Papers/ Conference-Papers/2009/09EPE.aspx. This paper states "Recovery boiler mass and energy balances are needed for performance testing of recovery boilers ... [however] the use of [TAPPI,1996] is problematic in Europe because of its view that losses from recovery of process chemicals are counted when determining the recovery boiler steam generation efficiency. Low efficiency leads to taxation and legislative problems in some European countries. ... This paper examines how [EN 12952-15:2003] can be applied to recovery boilers to find out net efficiency which is to be approximately [the] same [as] for other biomass boilers, not $10 \%$ lower."

"Water-Tube Boilers and Auxiliary Installations Part 15: Acceptance Tests", prEN 12952-15: November 1999, European Committee for Standardization, Brussels (also: CEN/TC 269/WG 3N 337); the draft European standard (reviewed in 2002); now EN 12952-15:2003 replacing the German and British standards. 